\title{
Seguro-desemprego brasileiro e salário de reinserção: análise empírica com regressão com descontinuidade e propensity score matching
}

Brazilian unemployment insurance and reinsertion wage: empirical analisys with discontinuity and propensity score matching

Gibran Teixeira

Universidade Federal do Rio Grande

Giácomo Balbinotto Neto

Universidade Federal do Rio Grande do Sul

\begin{abstract}
The objective of this article is to evaluate the influence of the Brazilian Unemployment Insurance program on their reinsertion wage of benefited. For the empirical analysis, we used the method of regression model Sharp discontinuity, as well as the propensity score matching as a criterion of robustness. Evaluating the results, one perceives that the national program goes of meeting to the theories, since sufficient did not reveal to influence the wage of reserve of the benefited ones. This indicates that the same act in order to assists financially the worker for a defined period of time without adding any level of human capital to their benefit.
\end{abstract}

\section{Keywords}

unemployment insurance; reinsertion wage; regression discontinuity; propensity score matching.

JEL Codes J64; J65.

\section{Resumo}

O objetivo deste artigo é avaliar a influência do programa brasileiro de Seguro-Desemprego sobre o salário de reinserção dos seus beneficiados. Como referenciais teóricos, foram utilizadas as teorias de JobSearch e do Capital Humano. Para a análise empirica, empregou-se o método de regressão com descontinuidade modelo Sharp, bem como o propensity score matching como critério de robustez.Avaliando os resultados, percebe-se que o programa nacional vai de encontro às teorias, visto que não se mostrou suficiente para influenciar o salário de reinserção dos beneficiados. Isso indica que ele atua no sentido de auxiliar financeiramente o trabalhador por um periodo definido de tempo sem agregar nenhum nivel de capital humano aos seus beneficiados.

\section{Palavras-chave}

seguro desemprego; salário de reinserção; regressão descontínua; propensity score matching.

Códigos JEL J64; J65. 


\section{Introdução}

O presente artigo tem por objetivo avaliar o impacto do Programa Seguro-Desemprego brasileiro sobre o salário de reinserção dos seus beneficiados, utilizando-se para tal os métodosde regressão com descontinuidade modelo Sharp, bem como o método propensity score matching. Segundo Fitzgerald (1998) e Pollak (2007), o efeito do benefício é no sentido de aumentar o salário de reinserção dos beneficiados. Assim, a hipótese a ser testada no artigo é identificar se esse efeito está ocorrendo no âmbito do Programa Seguro-Desemprego nacional.

$\bigcirc$ modo com que os programas sociais estão constituídos tem levado a um volume crescente de questionamentos, principalmente com relação a sua eficiência, tanto alocativa quanto distributiva. Camargo (2004) destaca que a questão é desenhar os programas de tal forma a gerar os incentivos corretos, induzindo a comportamentos considerados adequados pela sociedade, não provocando ineficiência na alocação de recursos; com isso, a preocupação com o desenho dos programas é tão importante quanto a própria existência. Nessa mesma perspectiva, porém especificamente para o Programa Seguro-Desemprego brasileiro, Chahad (1999) destaca que esse deveria ser integrado com redes de reinserção profissional como o Sistema Nacional de Emprego (SINE) e outras agências que possibilitassem ao trabalhador beneficiado efetiva procura por emprego e um retorno rápido ao mercado de trabalho formal, reduzindo o tempo de permanência do segurado no programa.

Entretanto, mesmo que o programa disponibilize nível maior de informações a respeito da oferta e da demanda de trabalho e direcione os trabalhadores beneficiados para as vagas em aberto, o trabalhador contemplado pelo programa ainda não terá um diferencial no mercado de trabalho. Com essa finalidade, Ambrózio (2003) formalizou um modelo teórico para o Programa Seguro-Desemprego, no qual os trabalhadores é que deveriam sinalizar para o mercado de trabalho a sua produtividade ao se inserirem em uma parcela maior ou menor do benefício, contudo sem o programa fornecer nenhuma espécie de treinamento profissional. Essa forma poderia diminuir o problema da assimetria de informação, que acaba por promover redução de postos de trabalho entre os trabalhadores que não possuem um diferencial para o mercado, como destacado por Camargo e Reis (2005). Já Chahad (2003) sugere alternativas para tornar o seguro um diferencial para 
o trabalhador; uma delas é promover, compulsoriamente, o recebimento do seguro, um treinamento profissional aos beneficiados, o que possibilitaria ao trabalhador um nível maior de capital humano e possivelmente uma reinserção no mercado de trabalho de modo mais rápido e com nível salarial mais elevado, visto que o recebimento do benefício, para o mercado, seria uma forma de sinalizar sobre a produtividade do trabalhador.

No entanto, antes mesmo de se propor determinada mudança em uma política pública, deve-se tentar identificar evidências de que a atual forma não está estruturada de maneira eficiente, especificamente para o Programa Seguro-Desemprego brasileiro; há a necessidade de informações que destaquem a não conformidade do programa com as exigências do mercado de trabalho nacional. Com essa finalidade, de promover nível maior de informação sobre influência do programa no mercado de trabalho brasileiro, o presente trabalho procura analisar se o fato de o trabalhador brasileiro passar pelo programa tem sido relevante para influenciar o seu salário de reinserção, já que uma das possibilidades dele é tornar o segurado um trabalhador com expectativa de ganhos maiores do que os trabalhadores que não recebem tal seguro, dado que, de acordo com a Constituição Federal de 1988, o programa visa promover ações integradas de orientação, recolocação e qualificação profissional.

Este artigo está dividido em cinco seções, incluindo esta introdução. $\mathrm{Na}$ segunda seção, avaliam-se os dois modelos teóricos que destacam o efeito do Programa Seguro-Desemprego sobre o salário de reinserção. Logo após, na terceira, discute-se a estratégia empírica com base em regressão com propensity score matching, bem como a fonte e a natureza dos dados. $\mathrm{Na}$ quarta, realiza-se a análise dos resultados dos modelos estimados. Por fim, na quinta, avaliam-se as principais constatações do trabalho.

\section{Discussão sobre seguro-desemprego e salário de reinserção}

As discussões sobre o Programa Seguro-Desemprego e seus possíveis efeitos sobre o mercado de trabalho, principalmente sobre a oferta de mão de obra, estão vinculadas à análise de modelos de Job Search e à Teoria do Capital Humano. Sendo assim, nas próximas subseções, destaca-se a análise desses dois modelos, respectivamente. 


\subsection{Job Search, seguro-desemprego e salário de reinserção}

De acordo com a teoria de Job Search, alguns fatores influenciam a oferta de mão de obra por parte dos trabalhadores e acabam fazendo com que esses decidam aceitar os salários oferecidos ou permanecer na situação de desemprego à procura de um emprego que lhes proporcione um salário maior. $\mathrm{O}$ modelo, a seguir, destaca algumas variáveis que interferem na decisão dos trabalhadores em aceitarem ou não, ofertarem trabalho no momento do desemprego; dentre elas, destaca-se o benefício seguro-desemprego.

Com base em Fitzgerald (1998), os trabalhadores maximizam o valor presente esperado da renda advinda do salário ao longo do tempo de permanência no mercado de trabalho, que pode ser escrito como:

$$
E \sum_{t=0}^{\infty} \beta^{t} y_{t}
$$

Onde $\beta$ é o fator de desconto que se encontra entre 0 e 1 , e $y$ representa a renda dos trabalhadores no período $t .{ }^{1}$ Considerando que $\left(y_{t}=w^{u}\right)$ se $o$ trabalhador está desempregado, e $\left(y_{t}=w\right)$, se empregado, sendo w o salário. O fator $\beta$ determina a taxa de desconto que será aplicada para trazer os ganhos futuros para o período $t$ e pode ser escrita como $1 /(1+r)$, onde $r$ é a taxa real de juros.

Como a questão a ser avaliada é a decisão do trabalhador em aceitar ou não propostas de emprego com base nas ofertas salariais, essa vai depender de uma análise comparativa entre as possíveis ofertas de trabalho que o trabalhador receberá dentro de determinado período. Se as chances de receber uma proposta melhor no período seguinte forem boas, então o trabalhador pode escolher rejeitar as propostas presentes com expectativa de conseguir um salário melhor nesse período vindouro, ou na semana seguinte, já que os períodos podem ser avaliados semanalmente.

Assim, considerando a função ganhos esperados, caso o trabalhador rejeite as ofertas de trabalho da semana dado por $V^{\text {espera }}(w)$; e $V^{\text {aceite }}(w)$, ser o valor presente dos ganhos salariais, caso o trabalhador aceite uma pro-

1 A hipótese de que os trabalhadores maximizam sua renda ao longo do tempo pode ser avaliada da seguinte maneira: (1) Pelo fato de trabalhadores serem neutros a risco; (2) pelo fato de eles estarem sempre revendo suas possibilidades de ofertar trabalho com base nas propostas de emprego a cada período, conforme McCall (1970). 
posta de emprego com um salário de $w$; e $V^{\text {oferta }}(w)$ ser o valor presente das ofertas de salário. Cada uma dessas três funções assume que o trabalhador desempregado vai maximizar a sua utilidade esperada descontada com base nas ofertas de salário apresentadas pelos empregadores, representada pela função (1).

A função rejeição ou espera por melhor oferta na semana posterior é dada por:

$$
V^{\text {espera }}(w)=w^{u}+\beta E V^{\text {oferta }}(w)
$$

Sendo o valor da função esperada dada por $E V^{\text {oferta }}$ (w), que é o valor esperado da oferta de trabalho a ser feita na nova semana, e $w^{u}$ o valor do benefício seguro-desemprego pago semanalmente. Considerando que as ofertas de trabalho são independentes e distribuídas semanalmente, a função espera permanece constante ao longo das semanas. ${ }^{2}$

Agora, considerando que o trabalhador aceite trabalhar por uma oferta de trabalho na semana de referência, essa pode ser expressa como:

$$
V^{\text {aceita }}(w)=w+\beta \alpha E V^{\text {oferta }}+\beta(1-\alpha) V^{\text {aceita }}(w)
$$

Se aceitar o emprego oferecido, o trabalhador receberá w de salário semanalmente. Entretanto, a cada fim de semana, ele tem probabilidade de $\alpha$, de receber uma nova oferta de trabalho, e (1- $\alpha$ ) é a probabilidade de o trabalhador permanecer no atual trabalho, sendo $\beta$ o fator de desconto tanto para o valor esperado das novas ofertas quanto o valor antecipado dos salários do atual emprego. Reescrevendo a equação (3) para a possibilidade de aceitar o emprego atual, tem-se:

$$
V^{\text {aceita }}(w)=\left\{\frac{w+\beta \alpha E V^{\text {oferta }}}{1-\beta(1-\alpha)}\right\}
$$

O dilema do trabalhador é qual o momento de aceitar a oferta de trabalho por um valor Vaceita (w), ou de rejeitá-la e continuar com determinado valor

2 Nesse modelo, não foi considerada a possibilidade de a função variar ao longo das semanas, visto que o interesse é ressaltar a influência do benefício sobre o salário de reinserção ou a função espera. Entretanto, autores como Do Monte, Araújo Junior e Pereira (2009) avaliaram que os trabalhadores brasileiros tendem a reduzir seus salários reserva com o decorrer do período de desemprego. 
de salário de reinserção ou salário de espera dado por $V^{\text {espera }}(w)$. O valor de ter uma oferta de emprego é dado por:

$$
V^{\text {oferta }}(w)=\max \left\{V^{\text {aceitar }}(w), V^{\text {espera }}(w)\right\}
$$

A equação (5) indica que o trabalhador vai avaliar a oferta de trabalho em função do salário oferecido e também do salário de reserva ou de espera. Caso o salário oferecido seja maior do que o valor de espera, o trabalhador aceita o novo emprego; caso contrário, ele continua esperando por uma oportunidade melhor.

A solução para o problema é encontrada com base nas funções $V^{\text {oferta }}(w)$, $V^{\text {aceita }}(w)$ e pela $V^{\text {espera }}(w)$. Considerando $V^{\text {espera }}(w)$ como constante, ou seja, definindo o salário de espera com base no benefício seguro-desemprego ou em qualquer outro benefício que o trabalhador possua ao longo do tempo de permanência na situação de desemprego, em última instância o trabalhador vai definir o momento de voltar ao mercado de trabalho, tendo em vista a oferta de trabalho e a sua possibilidade de novas oportunidades ao longo da semana.

Resolvendo o problema para o salário de reinserção, ou seja, um valor que satisfaça tanto $V^{\text {aceita }}(w)$ quanto $V^{\text {espera }}(w)$, tem-se:

$$
V^{\text {aceite }}\left(w^{r}\right)=V^{\text {espera }}\left(w^{r}\right)
$$

Ou, usando as equações (2) e (4), tem-se:

$$
\frac{w^{r}+\beta \alpha E V^{\text {oferta }}\left(w^{r}\right)}{1-\beta(1-\alpha)}=w^{u}+\beta \alpha E V^{\text {oferta }}\left(w^{r}\right)
$$

A expressão (7) indica que o salário de reinserção é identificado quando o salário aceito pelo trabalhador (lado esquerdo da equação) se iguala ao valor de rejeição da proposta, ou seja, o salário de reserva pode ser interpretado como o salário pelo qual o trabalhador se torna indiferente entre aceitar a oferta de trabalho ou permanecer na situação de desemprego à espera de uma oportunidade melhor, que, para o caso em análise, é o salário de reinserção dos trabalhadores. Antes de resolver o problema para o salário de reinserção ou (salário de reinserção), deve-se explicitar uma função para ele, 
podendo ser analisado como:

$$
E V^{\text {ofenta }}\left(w^{r}\right)=\left(\frac{1}{1-\beta}\right) \cdot\left[\frac{w^{u}+s\left(\bar{w}-w^{r}\right)^{2}}{2(\bar{w}-\underline{w})}\right]
$$

onde $s=\left[\frac{1}{(1-\beta(1-\alpha))}\right]$.

Substituindo a equação (8) em (7), chega-se à seguinte expressão para o salário de reinserção:

$$
w^{r}=w^{u}+\left[\frac{\beta(1-\alpha)}{1-\beta(1-\alpha)}\right] \cdot \frac{\left(\bar{w}-w^{r}\right)^{2}}{2(\bar{w}-\underline{w})}
$$

Entretanto, $w^{r}$ aparece em ambos os lados da expressão; assim, mais uma manipulação deve ser feita, como demonstra a equação (10), abaixo:

$$
\varphi\left(w^{r}\right)=\left[\frac{\beta(1-\alpha)}{1-\beta(1-\alpha)}\right] \cdot \frac{\left(\bar{w}-w^{r}\right)^{2}}{2(\bar{w}-\underline{w})}
$$

A função acima pode ser interpretada como o benefício esperado do novo salário ofertado pelo empregador, quando o trabalhador possui determinada proposta de salário $w^{r}$ à sua disposição. Nota-se que essa função é decrescente em $w^{r}$, indicando que o salário de reinserção diminui com o passar do tempo e que ofertas de emprego com salários maiores serão preferidas a continuar na situação de desemprego.

Agora, a partir de (10) e substituindo em (9), chega-se à seguinte equação:

$$
w^{r}=w^{u}+\varphi\left(w^{r}\right)
$$

A equação (11) determina o salário a ser aceito pelo trabalhador com base no seguro-desemprego e no salário de reinserção. Assim, o lado esquerdo da equação pode ser interpretado como o ganho mínimo esperado a ser oferecido pelos empregadores, para que o trabalhador aceite a oferta de emprego. Com isso, do ponto de vista da teoria JobSearch, o seguro-desemprego passa a ter influência sobre o salário a ser aceito pelo traba- 
lhador para retornar ao mercado de trabalho, justamente pelo fato de estar inserido no ganho esperado mínimo do trabalhador.

Além dessa discussão dada pela Teoria de JobSearch, o Programa Seguro-Desemprego pode ser retratado como o benefício que afeta o salário de reinserção também pela ótica do capital humano, como destacado a seguir.

\subsection{Teoria do Capital Humano, seguro-desemprego e salário de reinserção}

O efeito do Programa Seguro-Desemprego sobre a oferta de trabalho é ressaltado em Pollak (2007). Segundo o autor, a economia é formada por agentes que tem uma vida determinada com extensão de L períodos. E, em cada período j0 de sua vida, eles maximizam a utilidade esperada do seu tempo de vida. A função é separável no tempo em consumo e lazer.

$$
\operatorname{Max} E_{j_{0}}\left[\sum_{j=j_{o}}^{L} \beta^{J-j_{0}} U_{J}\left(c_{J}, l_{J}\right)+\beta^{L-j_{0}} V\left(a_{L+1}\right)\right]
$$

A função a ser maximizada (12) apresenta $U_{J}$ como a função de utilidade do período, que contém as propriedades usuais, como monotônica e respeitando as condições de I nada. $C_{J}$ é visto como o consumo no período J, L é o lazer no mesmo período, $\beta$ é o fator de desconto e $V($.) captura todas

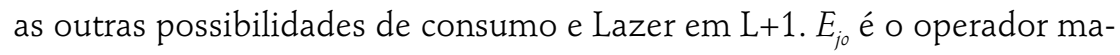
temático da expectativa condicional de todas as informações avaliadas no período $j_{0}$.

O modelo apresenta dois estados para os trabalhadores, ou empregados ou desempregados no primeiro período $L_{r-1}$ e depois esses passam a estar aposentados. Eles estão dotados com certa quantidade de lazer, $L^{u}$, por período. Os agentes, quando empregados, podem desfrutar de uma pequena quantidade de lazer $L^{e} \leq L^{u}$. Deixando $a_{j}$ ser os recursos próprios no período inicial $j_{0}$ e $Y_{j 0}$ ser o volume de renda (incluindo todo tipo de benefício, menos a rentabilidade do capital) recebido no mesmo período. Assim, a restrição orçamentária do período $j_{0}$ se mantém em toda a extensão da vida do agente:

$$
a_{j_{0}}+\sum_{J=j_{0}}^{L} R^{j_{0}-J}\left(Y_{J}-C_{j}\right)=R^{j_{0}-L} a_{L+1}
$$


Sendo R a taxa de juros livre de risco e $a_{L+1}$ é não negativo. Assim, a restrição orçamentária é identificada pela dotação de cada agente individualmente, e não somente por uma média. Isso implica que não existe um caminho seguro para as expectativas de flutuação da renda.

Os agentes começam sua vida desempregados, e os trabalhadores que têm uma dotação do emprego no período $J$ ganham um salário bruto, dado por:

$$
w_{j}=w\left(m_{j}, q_{j}, q\right) \equiv \varphi_{m j}\left(q_{j}+q\right)
$$

Onde $w_{j}$ é uma função crescente do tipo de trabalho $m_{j}$ e do componente individual corrente de capital humano (estoque de capital humano), destacado pela variável $q_{j}$ e outro elemento fixo $q$. Assim, $\varphi_{m j}$ é um parâmetro referente à escala, principalmente relacionado ao fator capital humano variável, ou seja, que tende a ser crescente com o tempo.

Entretanto, os trabalhadores empregados correm um risco periodicamente de perderem seus empregos, que é dado por $\lambda$. Em se tratando dos desempregados, esses recebem ofertas de trabalho a uma taxa $k$ e com distribuição de oferta de trabalho $G(m)$.

A questão central é que o risco de desemprego existe e é diferente para distintos trabalhadores, e com isso a renda futura ligada ao salário desses trabalhadores também passa a ser incerta. No entanto, para que os trabalhadores passem a ter renda estável ao longo de sua vida produtiva, é inevitável que ocorra uma formação de poupança por parte desses, salvo quando esses se aposentam.

Assim, o problema do agente pode ser escrito de maneira recursiva como:

$$
\begin{aligned}
& V_{j}\left(a_{j}, s_{j}, q_{j}, m_{j} \Omega_{j}\right)= \\
& =\operatorname{Max}\left\{u_{t}\left(c_{j}, l_{j}\right)+\beta E_{j} V_{j+1}\left(a_{j+1}, s_{j+1}, q_{j+1}, m_{j+1}, \Omega_{j+1}\right)\right\}
\end{aligned}
$$

Sujeita a uma restrição orçamentária dada por:

$$
a_{j+1}=R\left(a_{j}+y_{j}-c_{j}\right), a_{L+1} \geq 0
$$

Onde $a_{j+1}$ é uma função de transição do trabalhador do período $j$, com base em $a_{j}, s_{j}, q_{j}, m_{j}$ e $\Omega_{j}$. 
O valor da função $V_{j}$ (.) representa a utilidade descontada com o passar do tempo $j$, que pode ser caracterizada por uma função parametrizada. $O s_{j} \in\{e, u, r\}$ que representam o estado corrente do trabalhador, respectivamente, empregado, desempregado e aposentado, e $\Omega$ representa a captura de todas as informações relevantes sobre o histórico necessário para avaliar a renda do trabalhador.

Assim, $Y\left(j, a_{j}, s_{j}, w_{j}, \Omega_{j}\right)=w_{j}$ se $s_{j}=e ;$

$$
\text { e } 0 \text { caso contrário; }
$$

Com tudo mais permanecendo constante, o trabalhador recebe o salário pago pelo empregador, se ele tem um emprego, e não recebe nada, se ele estiver desempregado, e, se estiver aposentado, ele estará fora do mercado de trabalho ${ }^{3}$. Entretanto, em última instância, o trabalhador vai aceitar ou rejeitar oferta de trabalho com base em um patamar de salário $m$. Sendo $m \in \mathrm{M}$, o que implica $m \geq \underline{m}$, sendo $\underline{m}$ o mínimo necessário para tornar uma oferta de emprego aceitável pelo trabalhador.

Dessa forma, o ponto de referência $\underline{m}$ depende da situação corrente do trabalhador. Dado um estoque de capital humano $q_{j}$, que implica um nível ótimo de salário de reinserção dado por $\underline{m}=w\left(\underline{m}, q_{j}, q\right)$. Se a melhor oferta de salário para o trabalhador desempregado é dada por um $m \geq \underline{m}$, ela é aceita; caso contrário, o trabalhador permanece desempregado.

Agora, considerando a inclusão do Programa Seguro-Desemprego no mercado de trabalho, em que o governo provê um seguro ao trabalhador no valor de $b$, financiado por uma taxa proporcional no salário $\varphi$. Os ganhos futuros $Y$ tornam-se:

$$
\begin{aligned}
Y\left(j, a_{j}, s_{j}, w_{j}, \Omega_{j}\right)= & (1-\varphi) w_{j} \text { se } s_{j}=e ; \\
& b \text { se } s_{j}=u \\
& \text { e } 0 s_{j}=r .
\end{aligned}
$$

Segundo Pollak (2007), independentemente de o programa gerar capital humano aos trabalhadores beneficiados, no mínimo durante o recebimento desse, o salário de reinserção é positivamente alterado; já, se o capital encontram aposentados retornarem ao mercado de trabalho, fato que vem crescendo em dimensão, tanto no Brasil quanto no restante do mundo. 
humano é ampliado, o efeito do programa passa a ser definitivo sobre o salário de reinserção. $O$ que acaba por gerar alterações no mercado de trabalho, dentre elas a redução da taxa de aceitação de salários por parte dos trabalhadores, graças à elevação do salário de reinserção pedido pelos trabalhadores e por consequência o aumento da taxa de desemprego de equilíbrio da economia.

Assim, a questão a ser avaliada neste artigo é se os trabalhadores contemplados pelo Programa Seguro-Desemprego brasileiro se reinseriram com maiores salários pelo fato de terem sido beneficiados pelo programa ou não? A seguir, será detalhada a parte da aplicação, bem como o instrumental utilizado.

\section{Estratégia empírica}

Para identificar se o Programa Seguro-Desemprego está exercendo alguma influência sobre os salários de reinserção dos segurados, será utilizado um instrumental baseado em Regressões com Descontinuidade - RD, bem como através do método de score de propensão. Esses métodos acabam por se complementar, visto que o $\mathrm{RD}$ realiza a estimativa do efeito médio local do tratamento sobre os tratados; porém, a partir do momento em que as janelas em relação ao cut off são ampliadas, o efeito local acaba perdendo robustez, e, para tentar contrastar com o resultado do $\mathrm{RD}$, serão estimados os efeitos médios sobre os tratados com base no pareamento entre tratados e controles valendo-se de características observáveis dos grupos.

Na seção seguinte, são apresentadas as características fundamentais do modelo de Regressão com Descontinuidade com base na descontinuidade determinada pelo critério de elegibilidade do Programa Seguro-Desemprego brasileiro, vigente até junho de 2015. Logo após, destaca-se o método propensity score matching, e, por fim, analisa-se a fonte e a natureza dos dados.

\subsection{Definição da relação causal entre a participação no programa e a variável de impacto}

Seja $D$ a variável que define o critério de participação no programa vigente nos anos 2007, 2008 e 2009 (cut off score ou corte de tempo de permanên- 
cia no último emprego) e que ela seja determinada exclusivamente pelo tempo de permanência no último emprego $\mathrm{X}$, tal que:

$$
\mathrm{D}=1[\mathrm{X} \geq 6 \text { meses }]
$$

e a avaliação de interesse é o efeito de ser beneficiário do PSD sobre o novo salário de reinserção no mercado de trabalho, $y$. Os grupos $\mathrm{T}$ e $\mathrm{C}$ diferem em D. Assim, T é o grupo de trabalhadores que permaneceu nos seus últimos empregos no mínimo seis meses e que receberam o benefício $(D=1)$, e C é o grupo de trabalhadores com tempo de permanência no último emprego menor do que seis meses, não beneficiado pelo programa $(\mathrm{D}=0)$. Deste modo, o modelo deve destacar uma quebra ou uma descontinuidade no período de meses em que o trabalhador permaneceu no último emprego $\mathrm{X}$, a partir do cut off e gerar um desenho semelhante ao destacado na Figura 1.

Figura 1 Impacto hipotético do PSD nos novos salários dos trabalhadores

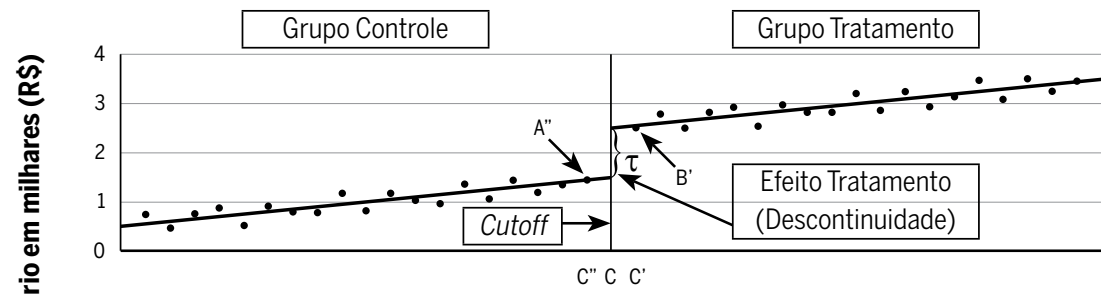

Meses de permanência do último emprego

Fonte: Elaborada pelo autor.

Sendo o indicador de tratamento $D_{i}$ uma regra de decisão determinística dada por:

$$
D_{i}=1\left[\bar{X} \geq X_{i}\right]
$$

onde $\bar{X}$ é um cut off conhecido, e $X$ é a variável de seleção. Os trabalhadores, portanto, são alocados para os grupos $\mathrm{T}$ e $\mathrm{C}$ somente com base na medida observável e contínua $X$, porém diferem exatamente em $D_{i}$. Ou seja, T é o grupo que permaneceu no mínimo $\bar{X}$ (ou $D_{i}=1$ ), e C é o grupo de que permaneceu no último emprego um período menor que $\bar{X}$ (ou $D_{i}=0$ ). 
Considerando agora o seguinte modelo de regressão:

$$
y_{i}=\propto+\beta_{i} D_{i}+u_{i} i=1, \ldots, n
$$

onde $u$ denota o termo de erro não observável, e $\beta_{i}$ é o parâmetro de interesse. Como $X$ é o único determinante sistemático de $D$, então $X$ capturaria qualquer correlação entre $D$ e $u$. Assim, no desenho SharpRD, se $D$ é independente de $y\left(D \perp y_{j}\right.$, para $\left.j=0,1\right)$, então a diferença média entre os grupos é identificada como $E\left(y_{1}-y_{0}\right)$. Neste caso, assume-se a hipótese de que:

$$
E[u \mid D, X]=E[u \mid X]
$$

Assim, os resultados potenciais em (19) para $y_{0}$ e $y_{1}$ seriam, respectivamente:

$$
\begin{aligned}
& y_{0}=\propto+u_{i} \\
& y_{1}-y_{0}=\beta_{i}
\end{aligned}
$$

Avaliando o choque ou a descontinuidade como o fato de o trabalhador se inserir no programa e receber o benefício, a questão é identificar o impacto no salário de reinserção dos trabalhadores que trabalharam no mínimo seis meses no último emprego e quando saíram receberam o benefício e comparar com os trabalhadores que permaneceram no último emprego menos do que os seis meses necessários ao recebimento do beneficio. Como o que determina o recebimento do programa é uma regra bem definida pelo Ministério do Trabalho e do Emprego, o design Sharp torna-se apropriado para avaliar se o programa está influenciando no salário de reinserção dos trabalhadores. Caso contrário, o desenho Fuzzy ${ }^{4}$ seria mais apropriado.

\subsubsection{Estimação do desenho Sharp RD}

A ideia por trás da estimação de um desenho $\mathrm{RD}$ está na constituição de uma amostra de indivíduos - similar a um experimento aleatorizado - em uma vizinhança do ponto definido como regra de seleção. Com isso, espe-

4 Para mais detalhamento sobre esse método, conferir Lee e Lemieux (2010). 
ra-se que os trabalhadores definidos próximo do cut off sejam semelhantes, gerando um resultado estimado para o efeito médio do tratamento.

Entretanto, nesse caso é necessário identificar algumas hipóteses sobre a forma funcional da regressão a ser estimada. Sendo elas:

$$
H_{1}=\lim _{X \rightarrow \bar{X}} E\left(u_{0} \mid X\right)=\lim _{X \rightarrow \bar{X}} E\left(u_{1} \mid X\right)
$$

$\mathrm{H} 2=g($.$) é uma função qualquer contínua em X=\bar{X}$.

A primeira hipótese garante que, próximo do cut off,os trabalhadores são semelhantes. Já a segunda, que identifica que $X$ é contínua, possibilita alterar acima e abaixo do cut off. Deste modo, a alternativa para estimar o efeito do tratamento seria a reespecificação do modelo (19) com a inclusão de $g\left(\mathrm{X}_{i}\right)$ como função-controle. Assim, obtem-se:

$$
y_{i}=\alpha+\beta_{i} D_{i}+g\left(X_{i}\right)+u_{i} \quad i=1, \ldots, n
$$

onde $u_{i} \equiv\left(1-D_{i}\right) u_{0 i}+D_{i} u_{1 i}$. Se $g\left(X_{i}\right)$ é linear, então $\beta_{i}$ pode ser obtido com base na diferença entre duas linhas de regressão paralelas ao cut off, igual à diferença entre os interceptos. Portanto, se a função-controle $g\left(X_{i}\right)$ for linear, o estimador do efeito comum do tratamento pode ser considerado não viesado, e o efeito do tratamento passa a ser representado pelo tamanho da descontinuidade, conforme ilustrado na Figura 1.

Tirando-se a diferença do resultado do tratamento entre trabalhadores que receberam e os que não receberam o $\mathrm{PSD}$, obtêm-se:

$$
y_{1 i}-y_{0 i}=\beta_{i}+u_{1}-u_{0}
$$

Aplicando-se $\mathrm{H}_{1}$ em (22):

$$
\lim _{X \rightarrow \bar{X}} E\left(y_{1}-y_{0} \mid X\right)=\beta_{i}+\lim _{X \rightarrow \bar{X}} E\left(u_{1}-u_{0} \mid X\right)=\beta_{i}
$$

onde $\beta_{i}$ é o efeito do tratamento para a subpopulação com tempo de permanência entre $X \simeq \bar{X}$.

Entretanto, para garantir que a probabilidade de participar do programa, $E\left(D_{i} \mid X_{i}\right)$, seja limitado entre 0 ou $1, \operatorname{Pr}[D=1 \mid X] \in[0,1]$, dependendo se $X_{i}<\bar{X}$ ou $X_{i} \geq \bar{X}$, deve-se observar que, no limite, tratados e controles diferem somente pelo fato de receberem o benefício, como destacado a seguir: 


$$
\begin{aligned}
& \lim _{\mathrm{X} \uparrow \overline{\mathrm{X}}} \mathrm{E}(\mathrm{y} \mid \mathrm{X})=\beta_{\mathrm{i}}+\lim _{\mathrm{X} \uparrow \overline{\mathrm{X}}} \mathrm{g}(\mathrm{X})+\lim _{\mathrm{X} \uparrow \overline{\mathrm{X}}} \mathrm{E}\left(\mathrm{u}_{1} \mid \mathrm{X}\right) \\
& \lim _{X \downarrow \bar{X}} E(y \mid X)=\beta_{i}+\lim _{X \downarrow \bar{X}} g(X)+\lim _{X \downarrow \bar{X}} E\left(u_{0} \mid X\right)
\end{aligned}
$$

o que implica:

$$
\lim _{X \uparrow \bar{X}} E(y \mid X)-\lim _{X \downarrow \bar{X}} E(y \mid X)=\beta_{i}+\lim _{X \uparrow \bar{X}} E\left(u_{1} \mid X\right)-\lim _{X \downarrow \bar{X}} E\left(u_{0} \mid X\right)
$$

onde $\beta_{i}$ é o efeito médio do tratamento. Para garantir que, na ausência do tratamento, indivíduos pertencentes à esquerda e à direita de $\bar{X}$ tenham resultados médios semelhantes, assumem-se as seguintes hipóteses de continuidade:

$$
\begin{aligned}
& \mathrm{H}_{3}=E\left(u_{i} \mid X\right) \text { é contínuo em } X=\bar{X} . \\
& \mathrm{H}_{4}=E\left(\beta_{i} \mid X\right) \text { é contínuo à direita de } X=\bar{X} .
\end{aligned}
$$

As funções a serem estimadas no trabalho via ajustamento global, em função de $\bar{X}$, são as seguintes:

$$
y_{i}=\propto+\theta T_{i}+\beta_{1}\left(X_{i}-\bar{X}\right)+\beta_{2} T_{i}\left(X_{i}-\bar{X}\right)+\beta_{3}\left(X_{i}-\bar{X}\right)^{2}+\beta_{4} C_{i}+e_{i}
$$

em que $T_{i}$ é simplesmente uma dummy de tratamento, $X$ está centrada em seu valor de corte, e $C$ representa as demais variáveis de controle que serão inseridas nas estimativas.

De acordo com Camelo (2010), o ajustamento da curva é dito global no sentido de usar todas as observações da amostra com o mesmo peso, em contraste com um ajustamento local em que se atribuem pesos diferenciados às observações. Este trabalho trata da estimação de um efeito de tratamento local; portanto, a estimação dessa função deverá ser feita em subamostras próximas ao ponto de corte, com diferentes covariadas interagindo, a fim de isolar o efeito em estudo. Essa proximidade, em princípio, é arbitrária; portanto, o modelo será estimado para diferentes intervalos em torno do cut off. Tal estratégia foi adotada em detrimento da não paramétrica definida por Nichols (2007), visto que permite avaliar os efeitos das covariadas sobre a variável explicada sem perder a robustez do efeito local do tratamento. 


\subsection{Propensity score matching}

Baseando-se nos dois grupos avaliados, nos controles e nos tratados, procedeu-se ao uso também do propensity score matching para encontrar trabalhadores não beneficiados pelo programa com o máximo possível de semelhança em características observáveis dos trabalhadores beneficiados, com vistas a minimizar o viés de seleção. Esse método, definido por Rosembaum e Rubin (1983), realiza o pareamento entre as observações do grupo avaliado e do grupo de controle utilizando a probabilidade de participação no programa, estimada como a probabilidade condicional de um grupo receber o tratamento dado às diversas características em comum. Assim, ele serve como contraponto ao resultado estimado pelo $\mathrm{RD}$, embora o resultado deste último esteja relacionado ao efeito médio local, e o propensity score matching, ao efeito médio do tratamento.

Para definir o propensity score (probabilidade de inclusão no Programa Seguro-Desemprego), estimou-se o seguinte modelo probit:

$$
P S D=\alpha+\sum_{i=2}^{5} \beta_{i} Z_{i}+\sum_{j=6}^{25} \beta_{j} X_{j}+\sum_{k=26}^{27} \beta_{k} N_{k}+\varepsilon
$$

Onde: $\quad P S D=$ Variável dummy que indica a participação no PSD;

$Z_{j}=$ Vetor de características regionais (Norte, Nordeste, Centro-Oeste, Sudeste e Sul);

$\mathrm{X}_{\mathrm{j}}=$ Vetor de características pessoais (sexo, faixas de idade, cor, faixa de anos de estudos, modo de inserção no mercado de trabalho, posição familiar, setor de atividade);

$\mathrm{N}_{\mathrm{k}}=$ Vetor que representa o período avaliado $(2007,2008,2009)$.

Depois de prever o propensity score, permitiu-se que cada observação do grupo avaliado fosse pareada a apenas uma observação do grupo de controle (pareamento sem reposição), considerada a mais próxima em probabilidade de participação do programa (não se diferenciassem em mais de 0,0001).

Como forma de robustez ao matching avaliado, estimou-se o modelo probit da equação 1, mas apenas para a amostra pareada. Se o matching foi bem ajustado, ou seja, se o grupo avaliado e o grupo de controle são semelhantes quanto às variáveis observáveis, as covariadas não deveriam explicar a probabilidade de participação no programa. Desse modo, se as 
observações pareadas dos grupos tratados e dos controles forem de fato semelhantes, as variáveis explicativas deveriam ser conjuntamente não significativas no modelo probit estimado para amostras pareadas. Isso pode ser verificado por meio do teste $\mathrm{F}$ de existência da regressão, ou mesmo pelos resultados dos testes $\mathrm{T}$ dos parâmetros estimados.

\subsection{Variáveis e fontes de dados}

Para construir o banco de dados, foi utilizada a Pesquisa Nacional por Amostra de Domicílio (PNAD) do período de 2007 a 2009. Nessas pesquisas, existem questões específicas relacionadas aos trabalhadores que saíram de algum trabalho no período de um ano anterior. Essa questão é dividida em duas: se o trabalhador permaneceu menos do que 11 meses no trabalho anterior, a questão é direcionada para uma resposta; caso o trabalhador tenha trabalhado mais do que um ano no trabalho anterior, a questão é direcionada à outra resposta. Isso se faz necessário explicar, uma vez que o banco de dados construído baseia-se na resposta referente aos trabalhadores que permaneceram até 11 meses no trabalho anterior, visto que o interesse é avaliar o efeito tratamento sobre pessoas bem próximas do período mínimo exigido para o requerimento ao programa. Por isso é que os resultados serão concentrados entre os trabalhadores dentro de um espectro de no mínimo um mês de experiência no trabalho anterior até 11 meses e que se encontravam novamente inseridos no mercado de trabalho no momento da entrevista, o que resultou em uma amostra de 2.832 , sendo que $10,87 \%$ desses foram contemplados pelo programa, e o restante foi utilizado como controle. Analisando-se o banco de dados, tem-se que ele é formado principalmente por trabalhadores oriundos da região Sudeste (43,6\%), Homens $(65,43 \%)$, de Raça Branca (46,46\%), com o Ensino Médio Completo ou Incompleto $(48,44 \%)$ e/ou com o Ensino Fundamental Completo ou Incompleto (35,49\%), de uma faixa etária de 26 a 35 anos (36,58\%) e de 15 a 25 anos (32,52\%). Esses trabalhadores estão vinculados na sua maioria com os setores do Comércio (24,5\%), Indústria (21,96\%) e Serviços (15,50\%), inseridos numa faixa salarial acima de 1 e no máximo de 2 salários mínimos $(50,38 \%)$ e que se reinseriram no mercado de trabalho com carteira de trabalho assinada (72,13\%). Com relação à permanência no último emprego, nota-se que uma gama razoável de trabalhadores permaneceu três meses 
(25,98\%), dois meses (18,85\%) e até um mês (17,79\%). Os valores salariais foram atualizados para o ano de $2009 \mathrm{com}$ base no IPCA do período. $O$ banco de dados pode ser visualizado na Tabela A.1, anexa.

Ao se comparar a amostra em análise com o perfil dos trabalhadores beneficiados pelo programa, retratado por Teixeira e Balbinotto Neto (2010), percebe-se que essa possui características semelhantes, visto que, na sua maioria, são trabalhadores oriundos da região Sudeste, o maior mercado de trabalho nacional, jovens, remanescentes dos principais setores da economia, Comércio, Indústria e Serviços, com um grau de instrução entre o ensino fundamental e/ou ensino médio completo ou incompleto e com uma remuneração na faixa entre um e dois salários mínimos, peculiaridades essas que foram encontradas na amostra. Segundo Marinho, Balestro e Walter (2010), apesar de o programa visar na sua essência o atendimento a uma ampla gama de perfis de trabalhadores, a prática demonstra que o público do programa em sua maioria tem sido de jovens e trabalhadores de meia idade com pouca experiência e com baixa qualificação profissional.

\section{Análise e discussão dos resultados}

A fim de avaliar o impacto do Programa Seguro-Desemprego no salário de reinserção dos beneficiados, realizou-se primeiramente uma análise de diferença de média entre os trabalhadores que receberam o auxílio quando saíram de seus empregos anteriores em comparação com os trabalhadores que não tinham tempo de emprego hábil para o recebimento desse. A Tabela 1, a seguir, retrata os valores dos testes.

Tabela 1 Teste de médias salariais simples

\begin{tabular}{lrr|r}
\hline Grupo & Observações & (R\$) Média & (Log) Média \\
\hline Controle & 2.524 & 850,73 & 6,532 \\
& & $(16,86)$ & $(0,012)$ \\
\hline Tratamento & \multirow{2}{*}{308} & $\begin{array}{r}868,64 \\
(47,35)\end{array}$ & 6,534 \\
& & $0,039)$ \\
\hline
\end{tabular}

Fonte: Elaborada pelo autor.

Com base na Tabela 1, é possível observar que o teste de diferença de média entre os grupos não foi significativo, indicando que não existem 
diferenças estatisticamente significativas entre os grupos de tratamento e controle. Isso significa que não existem diferenças salariais que possam ser captadas pelo teste de diferença de média entre os trabalhadores que receberam o seguro-desemprego e os que não receberam o benefício. Logo após, na tentativa de constatar uma possível diferença de salário entre os grupos, analisou-se a função densidade de Kernelda distribuição salarial da amostra, visto que ela pode indicar possíveis diferenças de densidade entre as faixas salariais.

Figura 2 Estimativa por Kernel da densidade salarial da amostra

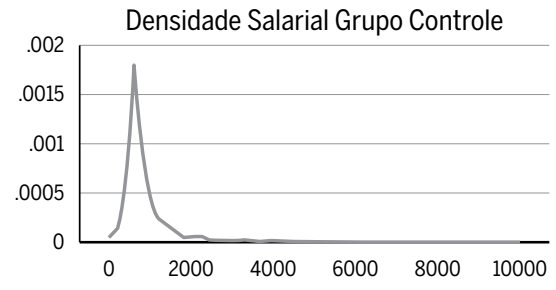

Rend Mensal Trabalho Principal

kernel $=$ epanechnikov, bandwidth $=50.0696$

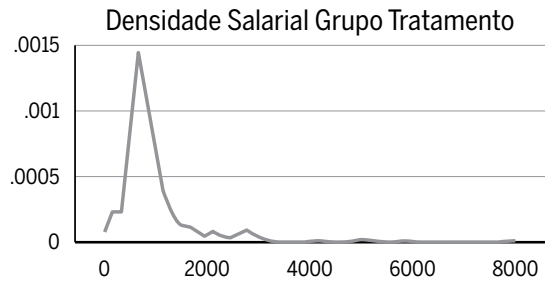

Rend Mensal Trabalho Principal

kernel $=$ epanechnikov, bandwidth $=91.4639$

Fonte: Elaborada pelo autor.

Ao analisar a Figura 2, constata-se que ocorre densidade maior entre os trabalhadores que ganham um e dois salários mínimos em ambas as distribuições, fato esse que indica a não existência de outra densidade salarial entre os grupos. No entanto, a fim de identificar uma possível descontinuidade nos ganhos entre os grupos de trabalhadores, em uma terceira etapa, estimaram-se cinco equações não paramétricas de diferenças de médias para distintas janelas de tempo próximas ao ponto de corte que podem indicar a presença ou não dessa diferença salarial.

As regressões não paramétricas dispostas na Tabela 2 são semelhantes ao teste de média identificado na Tabela 1. Entretanto, com esse tipo de instrumento, é possível quantificar a variação da média salarial entre os grupos, controlando por diferentes janelas de tempo de permanência no último emprego e principalmente entre os trabalhadores que ficaram entre 5 e 7 meses, que são aqueles que permaneceram um tempo muito próximo do limite para a requisição do benefício, que era de 6 meses. Os resultados das estimativas indicam que, entre os trabalhadores que tinham um mês de diferença do cutoff, a média de salários dos que receberam o auxílio foi 
menor em $\mathrm{R} \$ 83,692$; porém, esse resultado não foi estatisticamente significativo, assim como os demais parâmetros estimados. A seguir, na Tabela 3 , destaca-se a quarta etapa, que são as estimativas das regressões lineares locais, com as variáveis de controle, e também as dummy de interações, como especificada na equação (24).

Tabela 2 Regressão não paramétrica

\begin{tabular}{|c|c|c|c|c|c|}
\hline \multirow{2}{*}{ Tempo de emprego } & \multicolumn{2}{|c|}{ Coeficiente } & \multicolumn{2}{|c|}{ Desvio padrão } & \multirow{2}{*}{ Obs } \\
\hline & linear & $\log$ & linear & $\log$ & \\
\hline (1) Um mês & $-83,692$ & $-0,115$ & 81,331 & 0,057 & 548 \\
\hline (2) Um e dois meses & $-46,148$ & $-0,066$ & 64,417 & 0,049 & 996 \\
\hline (3) Um até três meses & $-24,211$ & $-0,034$ & 54,345 & 0,044 & 1.746 \\
\hline (4) Um até quatro meses & 8,856 & 0,018 & 53,094 & 0,043 & 2.286 \\
\hline (5) Um até cinco meses & 17,905 & 0,001 & 50,268 & 0,041 & 2.832 \\
\hline
\end{tabular}

Fonte: Elaborada pelo autor.

Tabela 3 Regressões lineares locais

\begin{tabular}{|c|c|c|c|c|c|c|c|c|}
\hline \multirow{4}{*}{ Variáveis } & \multicolumn{2}{|r|}{$\mathrm{TE}=1$} & \multicolumn{2}{|r|}{$\mathrm{TE}<=2$} & \multicolumn{2}{|r|}{$\mathrm{TE}<<=3$} & \multicolumn{2}{|r|}{$\mathrm{TE}<=4$} \\
\hline & Coef/(Dp) & Coef/(Dp) & Coef/(Dp) & Coef/(Dp) & Coef/(Dp) & Coef/(Dp) & Coef/(Dp) & Coef/(Dp) \\
\hline & $(n=548)$ & $(n=548)$ & $(n=1.526)$ & $(n=1.526)$ & $(n=1.746)$ & $(n=1.746)$ & $(n=2.286)$ & $(n=2.286)$ \\
\hline & Linear & Log & Linear & Log & Linear & $\log$ & Linear & Log \\
\hline R2 & $32,60 \%$ & $36,20 \%$ & $29,30 \%$ & $36,80 \%$ & $29,03 \%$ & $34,30 \%$ & $28,00 \%$ & $32,10 \%$ \\
\hline $\begin{array}{l}\text { Tempo } \\
\text { Emprego - TE }\end{array}$ & $\begin{array}{r}-143,261 \\
(136,548)\end{array}$ & $\begin{array}{r}0,019 \\
(0,089)\end{array}$ & $\begin{array}{r}-28,048 \\
(45,426)\end{array}$ & $\begin{array}{r}-0,007 \\
(0,027)\end{array}$ & $\begin{array}{r}-20,603 \\
(24,384)\end{array}$ & $\begin{array}{r}-0,167 \\
(0,091)\end{array}$ & $\begin{array}{r}-42,248 \\
(80,229)\end{array}$ & $\begin{array}{r}-0,044 \\
(0,053)\end{array}$ \\
\hline $\begin{array}{l}\text { Recebeu } \\
\text { Seguro - RS }\end{array}$ & $\begin{array}{r}171,587 \\
(195,457)\end{array}$ & $\begin{array}{r}-0,027 \\
(0,123)\end{array}$ & $\begin{array}{r}16,485 \\
(113,473)\end{array}$ & $\begin{array}{l}-0,026 \\
(0,071)\end{array}$ & $\begin{array}{r}-22,424 \\
(91,939)\end{array}$ & $\begin{array}{r}0,094 \\
(0,089)\end{array}$ & $\begin{array}{r}-25,171 \\
(111,791)\end{array}$ & $\begin{array}{l}-0,006 \\
(0,072)\end{array}$ \\
\hline TE*RS & - & - & - & - & $\begin{array}{r}108,019 \\
(253,204)\end{array}$ & $\begin{array}{r}0,265 \\
(0,154)\end{array}$ & $\begin{array}{r}78,992 \\
(128,225)\end{array}$ & $\begin{array}{r}0,069 \\
(0,086)\end{array}$ \\
\hline$(\mathrm{TE})^{2}$ & - & - & - & - & $\begin{array}{r}-20,871 \\
(35,530)\end{array}$ & $\begin{array}{r}-0,044 \\
(0,022)^{*}\end{array}$ & $\begin{array}{r}-12,145 \\
(15,020)\end{array}$ & $\begin{array}{l}-0,012 \\
(0,010)\end{array}$ \\
\hline Homem & $\begin{array}{r}300,024 \\
(91,330)^{*}\end{array}$ & $\begin{array}{r}0,216 \\
(0,053)^{*}\end{array}$ & $\begin{array}{r}295,072 \\
(63,105)^{*}\end{array}$ & $\begin{array}{r}0,225 \\
(0,037)^{*}\end{array}$ & $\begin{array}{r}319,940 \\
(50,285)\end{array}$ & $\begin{array}{r}0,259 \\
(0,029)^{*}\end{array}$ & $\begin{array}{r}319,781 \\
(42,015)^{*}\end{array}$ & $\begin{array}{r}0,275 \\
(0,025)^{*}\end{array}$ \\
\hline $\begin{array}{l}\text { Anos de } \\
\text { Estudo }\end{array}$ & & $\begin{array}{r}0,087 \\
(0,009)^{*}\end{array}$ & & $\begin{array}{r}0,089 \\
(0,006)^{*}\end{array}$ & & $\begin{array}{r}0,086 \\
(0,005)^{*}\end{array}$ & & $\begin{array}{r}0,079 \\
(0,004)^{*}\end{array}$ \\
\hline $\begin{array}{l}\text { Ensino } \\
\text { Fundamental }\end{array}$ & $\begin{array}{r}194,701 \\
(153,046) \\
\end{array}$ & & $\begin{array}{r}273,697 \\
(150,209)\end{array}$ & & $\begin{array}{r}241,817 \\
(98,835)^{*}\end{array}$ & & $\begin{array}{r}195,405 \\
(80,612)^{*}\end{array}$ & \\
\hline $\begin{array}{l}\text { Ensino } \\
\text { Médio }\end{array}$ & $\begin{array}{r}440,841 \\
(170,385)^{*}\end{array}$ & & $\begin{array}{r}533,022 \\
(170,323)^{*}\end{array}$ & & $\begin{array}{r}468,963 \\
(114,388)^{*}\end{array}$ & & $\begin{array}{r}413,621 \\
(93,457)^{*}\end{array}$ & \\
\hline
\end{tabular}




\begin{tabular}{|c|c|c|c|c|c|c|c|c|}
\hline \multirow{4}{*}{ Variáveis } & \multicolumn{2}{|r|}{$\mathrm{TE}=1$} & \multicolumn{2}{|r|}{$\mathrm{TE}<=2$} & \multicolumn{2}{|r|}{$\mathrm{TE}<=3$} & \multicolumn{2}{|r|}{$\mathrm{TE}<=4$} \\
\hline & Coef/(Dp) & Coef/(Dp) & Coef/(Dp) & Coef/(Dp) & Coef/(Dp) & Coef/(Dp) & Coef/(Dp) & Coef/(Dp) \\
\hline & $(n=548)$ & $(n=548)$ & $(n=1.526)$ & $(n=1.526)$ & $(n=1.746)$ & $(n=1.746)$ & $(n=2.286)$ & $(n=2.286)$ \\
\hline & Linear & $\log$ & Linear & $\log$ & Linear & Log & Linear & Log \\
\hline $\begin{array}{l}\text { Ensino } \\
\text { Superior }\end{array}$ & $\begin{array}{r}1.549,683 \\
(330,046)^{*}\end{array}$ & & $\begin{array}{r}1.533,228 \\
(249,656)^{*}\end{array}$ & & $\begin{array}{r}1.527,873 \\
(175,295)^{*}\end{array}$ & & $\begin{array}{r}1.408,821 \\
(147,135)^{*}\end{array}$ & \\
\hline $\begin{array}{l}\text { Experiência } \\
\text { Profissional }\end{array}$ & & $\begin{array}{r}0,024 \\
(0,008)^{*}\end{array}$ & & $\begin{array}{r}0,022 \\
(0,005)^{*}\end{array}$ & & $\begin{array}{r}0,020 \\
(0,004)^{*}\end{array}$ & & $\begin{array}{r}0,018 \\
(0,003)^{*}\end{array}$ \\
\hline $\begin{array}{l}\text { (Experiência } \\
\text { Profissional) }^{2}\end{array}$ & - & $\begin{array}{r}-0,0003 \\
(0,0001)^{*}\end{array}$ & & $\begin{array}{r}-0,0001 \\
(0,0001)\end{array}$ & & $\begin{array}{r}-0,0001 \\
(0,00009)\end{array}$ & & $\begin{array}{r}-0,0001 \\
(0,00007)\end{array}$ \\
\hline Carteira & $\begin{array}{r}88,916 \\
(77,189) \\
\end{array}$ & $\begin{array}{r}0,2383 \\
(0,066)^{*}\end{array}$ & $\begin{array}{r}155,302 \\
(58,703)^{*}\end{array}$ & $\begin{array}{r}0,202 \\
(0,046)^{*}\end{array}$ & $\begin{array}{r}145,716 \\
(46,709)^{*}\end{array}$ & $\begin{array}{r}0,227 \\
(0,035)^{*}\end{array}$ & $\begin{array}{r}111,393 \\
(39,376)^{*}\end{array}$ & $\begin{array}{r}0,219 \\
(0,031)^{*}\end{array}$ \\
\hline Branca & $\begin{array}{r}62,573 \\
(182,898)\end{array}$ & $\begin{array}{r}0,219 \\
(0,085)^{*}\end{array}$ & $\begin{array}{r}131,686 \\
(104,891)\end{array}$ & $\begin{array}{r}0,154 \\
(0,046)^{*}\end{array}$ & $\begin{array}{r}87,098 \\
(72,088)\end{array}$ & $\begin{array}{r}0,125 \\
(0,042)^{*}\end{array}$ & $\begin{array}{r}89,237 \\
(59,225)\end{array}$ & $\begin{array}{r}0,124 \\
(0,036)^{*}\end{array}$ \\
\hline Parda & $\begin{array}{r}24,561 \\
(159,484) \\
\end{array}$ & $\begin{array}{r}0,080 \\
(0,083) \\
\end{array}$ & $\begin{array}{r}-24,460 \\
(90,838)\end{array}$ & $\begin{array}{r}0,001 \\
(0,056) \\
\end{array}$ & $\begin{array}{r}-30,684 \\
(65,461)\end{array}$ & $\begin{array}{r}-0,0009 \\
(0,041) \\
\end{array}$ & $\begin{array}{r}-25,410 \\
(54,289)\end{array}$ & $\begin{array}{r}0,001 \\
(0,035) \\
\end{array}$ \\
\hline Chefe & $\begin{array}{r}-26,215 \\
(134,044) \\
\end{array}$ & $\begin{array}{r}0,028 \\
(0,071)^{*}\end{array}$ & $\begin{array}{r}-35,438 \\
(90,015)\end{array}$ & $\begin{array}{r}0,003 \\
(0,049)\end{array}$ & $\begin{array}{r}-57,048 \\
(61,441) \\
\end{array}$ & $\begin{array}{r}-0,021 \\
(0,036)\end{array}$ & $\begin{array}{r}-58,951 \\
(50,596)\end{array}$ & $\begin{array}{r}-0,038 \\
(0,032)\end{array}$ \\
\hline Filho & $\begin{array}{r}-197,731 \\
(128,806)\end{array}$ & $\begin{array}{r}-0,085 \\
(0,073)^{*}\end{array}$ & $\begin{array}{r}-189,874 \\
(83,987)^{*}\end{array}$ & $\begin{array}{r}-0,103 \\
(0,050)^{*}\end{array}$ & $\begin{array}{r}-188,998 \\
(59,679)^{*}\end{array}$ & $\begin{array}{r}-0,134 \\
(0,039)^{*}\end{array}$ & $\begin{array}{r}-191,832 \\
(48,650)^{*}\end{array}$ & $\begin{array}{r}-0,133 \\
(0,036)^{*}\end{array}$ \\
\hline $\begin{array}{l}\text { De } 26 \text { até } \\
35 \text { anos }\end{array}$ & $\begin{array}{r}32,983 \\
(70,838)\end{array}$ & - & $\begin{array}{r}136,907 \\
(42,805)^{*}\end{array}$ & 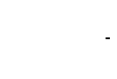 & $\begin{array}{r}132,752 \\
(33,123)^{*}\end{array}$ & & $\begin{array}{r}109,743 \\
(28,224)^{*}\end{array}$ & \\
\hline $\begin{array}{l}\text { De } 36 \text { até } \\
45 \text { anos }\end{array}$ & $\begin{array}{r}251,651 \\
(98,739)^{*}\end{array}$ & & $\begin{array}{r}321,042 \\
(80,484)^{*}\end{array}$ & & $\begin{array}{r}271,023 \\
(57,859)^{*}\end{array}$ & & $\begin{array}{r}250,669 \\
(49,877)^{*}\end{array}$ & \\
\hline $\begin{array}{l}\text { De } 45 \text { até } \\
55 \text { anos }\end{array}$ & $\begin{array}{r}333,785 \\
(201,982)\end{array}$ & 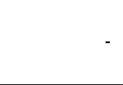 & $\begin{array}{r}619,167 \\
(190,105)^{*}\end{array}$ & & $\begin{array}{r}507,360 \\
(117,181)^{*}\end{array}$ & & $\begin{array}{r}429,069 \\
(94,295)^{*}\end{array}$ & \\
\hline $\begin{array}{l}\text { Acima de } \\
55 \text { anos }\end{array}$ & $\begin{array}{r}511,337 \\
(242,139)^{*}\end{array}$ & & $\begin{array}{r}469,143 \\
(193,002)^{*}\end{array}$ & & $\begin{array}{r}747,437 \\
(238,217)^{*}\end{array}$ & & $\begin{array}{r}597,279 \\
(188,164)^{*}\end{array}$ & \\
\hline Agricola & $\begin{array}{r}-12,820 \\
(95,945)\end{array}$ & $\begin{array}{r}0,029 \\
(0,122)\end{array}$ & $\begin{array}{r}-58,554 \\
(85,454)\end{array}$ & $\begin{array}{r}0,040 \\
(0,078)\end{array}$ & $\begin{array}{r}-84,823 \\
(63,319)\end{array}$ & $\begin{array}{r}-0,033 \\
(0,056)\end{array}$ & $\begin{array}{r}-62,514 \\
(48,581) \\
\end{array}$ & $\begin{array}{r}-0,046 \\
(0,045)\end{array}$ \\
\hline Indústria & $\begin{array}{r}3,787 \\
(96,112) \\
\end{array}$ & $\begin{array}{r}-0,087 \\
(0,084)\end{array}$ & $\begin{array}{r}26,136 \\
(98,845)\end{array}$ & $\begin{array}{r}-0,055 \\
(0,058)\end{array}$ & $\begin{array}{r}18,684 \\
(73,184)\end{array}$ & $\begin{array}{r}-0,065 \\
(0,045)\end{array}$ & $\begin{array}{r}43,911 \\
(57,265) \\
\end{array}$ & $\begin{array}{l}-0,042 \\
(0,038) \\
\end{array}$ \\
\hline Comércio & $\begin{array}{r}-45,084 \\
(87,425)\end{array}$ & $\begin{array}{r}-0,140 \\
(0,089)\end{array}$ & $\begin{array}{r}-76,193 \\
(88,695)\end{array}$ & $\begin{array}{r}-0,116 \\
(0,059)^{*}\end{array}$ & $\begin{array}{r}-81,276 \\
(66,461)\end{array}$ & $\begin{array}{r}-0,138 \\
(0,045)^{*}\end{array}$ & $\begin{array}{r}-39,859 \\
(52,648)\end{array}$ & $\begin{array}{r}-0,104 \\
(0,038)^{*}\end{array}$ \\
\hline Transporte & $\begin{array}{r}-38,445 \\
(117,440)\end{array}$ & $\begin{array}{r}-0,016 \\
(0,109)\end{array}$ & $\begin{array}{r}-41,420 \\
(151,060)\end{array}$ & $\begin{array}{r}-0,029 \\
(0,078)\end{array}$ & $\begin{array}{r}-47,097 \\
(100,013)\end{array}$ & $\begin{array}{r}-0,036 \\
(0,057)\end{array}$ & $\begin{array}{r}2,794 \\
(81,768) \\
\end{array}$ & $\begin{array}{r}0,013 \\
(0,050)\end{array}$ \\
\hline Serviços & $\begin{array}{l}-138,787 \\
(88,470)\end{array}$ & $\begin{array}{r}-0,226 \\
(0,099)^{*}\end{array}$ & $\begin{array}{r}-200,747 \\
(90,276)^{*}\end{array}$ & $\begin{array}{r}-0,239 \\
(0,068)^{*}\end{array}$ & $\begin{array}{r}-128,359 \\
(83,264)\end{array}$ & $\begin{array}{r}-0,214 \\
(0,054)^{*}\end{array}$ & $\begin{array}{r}-79,973 \\
(68,188)\end{array}$ & $\begin{array}{r}-0,184 \\
(0,046)^{*}\end{array}$ \\
\hline Adm.Pública & $\begin{array}{r}-291,942 \\
(152,542)\end{array}$ & $\begin{array}{r}-0,178 \\
(0,168)\end{array}$ & $\begin{array}{r}-124,784 \\
(234,565)\end{array}$ & $\begin{array}{r}-0,145 \\
(0,122)\end{array}$ & $\begin{array}{r}-115,590 \\
(179,360)\end{array}$ & $\begin{array}{r}-0,123 \\
(0,097)\end{array}$ & $\begin{array}{r}-63,099 \\
(149,001)\end{array}$ & $\begin{array}{r}-0,031 \\
(0,086)\end{array}$ \\
\hline
\end{tabular}




\begin{tabular}{|c|c|c|c|c|c|c|c|c|}
\hline \multirow{4}{*}{ Variáveis } & \multicolumn{2}{|r|}{$\mathrm{TE}=1$} & \multicolumn{2}{|r|}{$\mathrm{TE}<=2$} & \multicolumn{2}{|r|}{$\mathrm{TE}<=3$} & \multicolumn{2}{|r|}{$\mathrm{TE}<=4$} \\
\hline & Coef/(Dp) & Coef/(Dp) & Coef/(Dp) & Coef/(Dp) & Coef/(Dp) & Coef/(Dp) & Coef/(Dp) & Coef/(Dp) \\
\hline & $(n=548)$ & $(n=548)$ & $(n=1.526)$ & $(n=1.526)$ & $(n=1.746)$ & $(n=1.746)$ & $(n=2.286)$ & $(n=2.286)$ \\
\hline & Linear & $\log$ & Linear & Log & Linear & Log & Linear & Log \\
\hline \multirow{2}{*}{$\begin{array}{l}\text { Outras } \\
\text { Atividades }\end{array}$} & 189,623 & $-0,005$ & $-1,736$ & $-0,069$ & $-34,303$ & $-0,103$ & 8,090 & $-0,059$ \\
\hline & $(168,075)$ & $(0,102)$ & $(128,823)$ & $(0,072)$ & $(93,220)$ & $(0,055)^{*}$ & $(74,162)$ & $(0,047)$ \\
\hline \multirow{2}{*}{ Nordeste } & $-13,070$ & $-0,049$ & 69,346 & 0,021 & 9,792 & $-0,011$ & 4,763 & $-0,008$ \\
\hline & $(84,221)$ & $(0,080)$ & $(70,615)$ & $(0,056)$ & $(69,508)$ & $(0,046)$ & $(55,745)$ & $(0,039)$ \\
\hline \multirow{2}{*}{ Sudeste } & 187,577 & 0,135 & 201,712 & 0,155 & 126,546 & 0,125 & 103,084 & 0,115 \\
\hline & $(84,510)$ & $(0,071)$ & $(64,958)^{*}$ & $(0,051)^{*}$ & $(64,732)^{*}$ & $(0,042)^{*}$ & $(51,197)^{*}$ & $(0,036)^{*}$ \\
\hline \multirow{2}{*}{ Sul } & 156,024 & 0,129 & 105,317 & 0,098 & 11,693 & 0,041 & 20,995 & 0,041 \\
\hline & $(102,582)$ & $(0,078)$ & $(71,353)$ & $(0,054)^{*}$ & $(69,581)$ & $(0,046)$ & $(56,577)$ & $(0,040)$ \\
\hline \multirow{2}{*}{ Centro-Oeste } & $-56,746$ & $-0,004$ & 72,128 & 0,111 & 51,201 & 0,117 & 127,779 & 0,153 \\
\hline & $(144,750)$ & $(0,188)$ & $(94,940)$ & $(0,081)$ & $(79,326)$ & $(0,060)$ & $(84,366)$ & $(0,059)^{*}$ \\
\hline \multirow{2}{*}{$\begin{array}{l}\text { Outras } \\
\text { Atividades }\end{array}$} & 189,623 & $-0,005$ & $-1,736$ & $-0,069$ & $-34,303$ & $-0,103$ & 8,090 & $-0,059$ \\
\hline & $(168,075)$ & $(0,102)$ & $(128,823)$ & $(0,072)$ & $(93,220)$ & $(0,055)^{*}$ & $(74,162)$ & $(0,047)$ \\
\hline \multirow{2}{*}{2009} & $-45,219$ & 0,066 & 2,509 & 0,042 & 23,509 & 0,032 & 33,476 & 0,032 \\
\hline & $(81,011)$ & $(0,056)$ & $(53,505)$ & $(0,037)$ & $(38,932)$ & $(0,027)$ & $(31,524)$ & $(0,023)$ \\
\hline \multirow{2}{*}{2008} & $-51,752$ & 0,076 & 120,679 & 0,096 & 98,511 & 0,052 & 97,039 & 0,045 \\
\hline & $(95,006)$ & $(0,067)$ & $(81,082)$ & $(0,047)$ & $(61,343)$ & $(0,036)$ & $(49,966)^{*}$ & $(0,031)$ \\
\hline
\end{tabular}

Fonte: Elaborada pelo autor.

*Os valores que apresentam (*) foram significativos com $90 \%$ ou mais de confiança. As variáveis: Norte, Mulher, Ensino Básico, Sem Carteira, Negra, Cônjuge, 2007, C. Civil e até 25 anos foram utilizadas como base para as demais. As estimativas foram realizadas no modo robusto à heterocedasticidade. Um quinto modelo foi estimado, levando em consideração cinco meses de diferença do cutoff; porém, os resultados foram os mesmos obtidos pelo quarto modelo, e no primeiro modelo não foi possível avaliar as interações das variáveis (-) por causa do baixo número de observações dos tratados. Outras estimativas foram feitas considerando o cutoff diferente dos seis meses; isso serve como placebo temporal para avaliar a robustez dos modelos estimados; eles se encontram anexos nas Tabelas A.2, A.3 e A.4, além de validar os controles.

A Tabela 3 retrata as estimativas da variável salário de reinserção em $\mathrm{R} \$$ e em logaritmo natural e com quatro diferentes intervalos de tempo. Avaliando os resultados dos modelos, é possível identificar que as variáveis tempo de permanência no emprego anterior e recebeu seguro desemprego - não foram estatisticamente significativas para a reinserção dos trabalhadores em faixas salariais maiores nos quatro modelos analisados para cada uma das especificações. No primeiro modelo, utilizou-se um período de tempo de um mês de diferença, acima e abaixo do tempo necessário para o recebimento do benefício e assim, sucessivamente, até chegar ao quarto, com quatro meses de diferença para ambos os lados do cutoff. 
Ao analisar os modelos com a variável de interesse em $\mathrm{R}$, constatou-se um diferencial salarial favorável aos homens no montante que variou entre $\mathrm{R} \$ 295,072$ e $\mathrm{R} \$ 319,940$, além da existência de um diferencial salarial entre as faixas de escolaridade, revelando um aumento entre $\mathrm{R} \$ 195,405$ e $\mathrm{R} \$ 241,817$ a mais para os trabalhadores que possuem o ensino fundamental em relação aos trabalhadores que possuem o ensino básico. A diferença também foi significativa para os trabalhadores com o ensino médio, variação salarial entre $\mathrm{R} \$ 413,621$ e R \$533,022; a maior diferença salarial foi constatada entre os trabalhadores que possuem o ensino superior em relação aos que possuem o ensino básico, variando entre $\mathrm{R} \$ 1.408,821$ e $\mathrm{R} \$ 1.549,683$.

Outra questão que se mostrou relevante para o aumento salarial foi a formalização; embora não sendo significativo no primeiro modelo, nos demais essa variável se mostrou capaz de influenciar favoravelmente o aumento dos salários dos trabalhadores e variou entre $\mathrm{R} \$ 111,393$ e $\mathrm{R} \$ 155,302$. Isso ressalta que, conseguindo se inserir com carteira de trabalho assinada, além de receber todos os benefícios da Previdência Social,o trabalhador ainda pode obter um salário mais elevado do que no mercado informal.

Com respeito à faixa etária, foi possível evidenciar que os trabalhadores com idade mais avançada acabam ganhando mais do que os jovens até 25 anos de idade, visto que os trabalhadores com idade acima de 55 anos receberam entre $\mathrm{R} \$ 469,143$ e $\mathrm{R} \$ 747,437$. Já os trabalhadores da faixa acima de 45 até 55 anos receberam entre $\mathrm{R} \$ 429,069$ e $\mathrm{R} \$ 619,167$ a mais do que os jovens até 25 anos, e os trabalhadores da faixa acima de 35 até os 45 anos de idade receberam entre $R \$ 250,669$ e $R \$ 321,042$, e os jovens acima de 25 anos até 35 apresentaram diferenças entre $\mathrm{R} \$ 109,743$ e 136,907 em relação aos jovens até 25 anos. Essa diferença também pode ser constatada via análisedos jovens considerados como filhos na posição familiar que receberam entre $\mathrm{R}$ \$ 188,998 e R \$ 191,832 a menos do que os considerados como cônjuges.

Além dessas estimativas, realizou-se outra análise com base na variável dependente em logaritmo natural, bem como com a inclusão de variáveis como experiência profissiona $1^{5}$ e anos de estudo, sendo esta última avaliada por ano de estudo completado, e não por classes como anteriormente. Os resultados encontrados convergem com os anteriores, ressaltando-se 5 Para o cálculo da experiência profissional, utilizou-se o modelo apresentado por Mincer (1974), no qual tal variável pode ser analisada como uma relação da idade e também do tempo de estudo do trabalhador, sendo avaliada como: Experiência = Idade $-\mathrm{S}-6$, onde S é número de anos de estudo. Além disso, assumiu-se que o trabalhador entre na orça de trabalho somente após completar a sua educação. 
mais uma vez que o recebimento do benefício seguro-desemprego não foi estatisticamente significativo para impactar o salário de reinserção dos beneficiados, assim como o tempo de permanência no último emprego. Além desse, outros se mostraram novamente significantes para impactar o salário de reinserção dos trabalhadores, como o caso de os trabalhadores serem oriundos da região Sudeste, variando entre $11,5 \%$ e $15,5 \%$ a mais em termos salariais do que os oriundos da região Norte. A variável gênero se mostrou significativa, com valores salariais variando entre $21,60 \%$ e $27,50 \%$, favorável aos homens em relação às mulheres. A questão do capital humano também foi significativa para promover a reinserção profissional dos trabalhadores em níveis salariais mais elevados, visto que as estimativas captaram uma variação entre 7,90\% e 8,90\% de remuneração para cada ano a mais de estudo dos trabalhadores.

No caso da experiência profissional, constatou-se que cada ano a mais de experiência profissional dos trabalhadores gera entre $1,80 \%$ e $2,40 \%$ a mais de salário no momento de se reinserirem no mercado de trabalho brasileiro. Outra variável que novamente se mostrou significativamente influente sobre o salário de reinserção dos trabalhadores foi a formalização, indicando que os trabalhadores que se reinseriram com carteira de trabalho assinada tiveram ganho entre $20,20 \%$ e $23,83 \%$ a mais do que aqueles que se reinseriram de modo informal. As variáveis cor, posição familiar e setor de atividade se mostraram também estatisticamente significativas. No entanto, a que se destaca é a cor, visto que os trabalhadores de cor branca se reinseriram no mercado de trabalho, ganhando entre $12,40 \%$ e $21,90 \%$ a mais do que os demais trabalhadores dessa variável. Quanto à posição familiar, os filhos se reinseriram com um salário menor, entre 8,50\% e 13,40\% em relação aos cônjuges, e os trabalhadores do comércio e dos serviços se reinseriram com um salário menor, respectivamente, entre 10,40\% e 14\% e entre $18,40 \%$ e $23,40 \%$ do que os trabalhadores da construção civil, questões essas que o modelo anterior também havia captado.

Como forma de robustez aos resultados encontrados pelo $\mathrm{RD}$, estimou-se o efeito médio do tratamento com base no método de propensity score matching. Embora o entorno da regra que gera a descontinuidade seja estimado o efeito local médio, a partir do aumento das janelas de tempo, esse resultado se enfraquece, e, como forma de complementar os resultados com o efeito médio do tratamento, compararam-se os resultados do $\mathrm{RD}$ com os do propensity score matching. Os resultados encontrados via esti- 
mativa do propensity score matching vão ao encontro dos estimados pelo $\mathrm{RD}$, sendo que a diferença dos salários entre os beneficiários e não beneficiários, após o pareamento, não foi estatisticamente significativa, como destacado pela Tabela 4, a seguir.

Tabela 4 Análise propensity score matching sobre o salário de reinserção

\begin{tabular}{l|l|r|r|r|r}
\hline Variáveis* $^{*}$ & Amostra & Tratados & Controles & Diferença & Desvio \\
\hline \multirow{2}{*}{ Salário em R\$ } & Não Pareada & 879,977 & 835,525 & 44,451 & 50,614 \\
\cline { 2 - 6 } & Pareada & 879,977 & 850,729 & 29,248 & 81,316 \\
\hline \multirow{2}{*}{ Salário em Log } & Não Pareada & 6,547 & 6,540 & 0,007 & 0,036 \\
\cline { 2 - 6 } & Pareada & 6,547 & 6,543 & 0,004 & 0,060 \\
\hline
\end{tabular}

Fonte: Elaborada pelo autor.

*Os resultados dos modelos utilizados nos pareamentos podem ser visualizados na Tabela A.4, assim como os resultados da checagem de cada pareamento.

Após o pareamento, obteve-se um número de 254 tratados e 2.286 controles em ambas as amostras avaliadas. Com base na Tabela 4, reforça-se via propensity score matching que o fato de o trabalhador ingressar no Programa Seguro-Desemprego não influencia o salário de reinserção. Esse resultado converge para o fato de que tal programa brasileiro está estruturado no sentido de garantir renda ao trabalhador beneficiado por um determinado período de tempo sem promover nenhuma agregação de capital humano, o que alimenta ainda mais o círculo vicioso da dependência dos trabalhadores pelo programa além de incentivar o aumento da rotatividade do mercado de trabalho nacional, como ressaltado por Camargo (2004).

\section{Considerações finais}

O presente artigo buscou avaliar de forma empírica a influência do Programa Seguro-Desemprego brasileiro sobre o salário de reinserção dos seus beneficiados. Para tanto, foram utilizadas como bases teóricas a Teoria de Job Search e a Teoria do Capital Humano, ambas destacando que o Programa Seguro-Desemprego pode influenciar o salário de reinserção de seus beneficiados.

Para identificar de forma empírica a influência do programa sobre o salário de reinserção dos beneficiados, utilizou-se o instrumental de Regressões com Descontinuidade, apropriado para avaliar impactos em que o 
efeito do tratamento é identificado por uma regra de decisão bem definida, como o caso do programa nacional. No entanto, esse tipo de instrumento é válido somente para um número determinado de segurados, aqueles próximos ao ponto de corte ou cut off, que, no caso em questão, avaliado no tempo mínimo exigido para o trabalhador requerer o auxílio de 6 meses; entretanto, a faixa avaliada variou de 1 a 11 meses de permanência no último emprego. Além do $\mathrm{RD}$, que estimou o efeito local médio, utilizou-se o propensity score matching, empregado para realizar o pareamento entre controles e tratados com base em características observáveis e estimar o efeito médio do tratamento como forma de robustez às estimativas realizadas pelo $\mathrm{RD}$. Os resultados encontrados indicaram que o programa não está exercendo nenhuma alteração significativa no salário de reinserção dos seus beneficiados. Isso pode ser explicado pelo fato de o programa não agregar de forma abrangente um nível de capital humano aos trabalhadores que usufruem dele, bem como o tempo necessário para a reinserção no mercado de trabalho brasileiro pode estar acima do número de parcelas disponibilizadas pelo programa, sendo assim um auxílio que garante renda por um determinado período, porém não é determinante para que os trabalhadores possam se reinserir com um salário mais elevado.

Além de analisar a influência do programa, foi possível constatar que os homens ainda recebem mais do que as mulheres, no mercado de trabalho nacional, bem como a importância do nível educacional e da experiência profissional para reinserção com níveis salariais mais elevados. De posse dessas constatações, como indicação para a formatação do Programa Seguro-Desemprego brasileiro, sugere-se que esse seja pensado e estruturado de forma a gerar nível maior de informação do mercado de trabalho aos quais os beneficiados estão inseridos, bem como agregar algum tipo de capital humano a eles, oferecendo cursos de qualificação profissional, treinamentos e reciclagens, visto que, somente dessa forma, é que o seu maior público, jovens e trabalhadores de meia idade, de pouca instrução, poderão se reinserir no mercado de trabalho de modo mais rápido, estável e com nível salarial melhor.

\section{Referências}

AMBRÓZIO, A. M. H. P. Três ensaios sobre imperfeições no mercado de trabalho. 2003. Tese (Doutorado em economia) - Departamento de economia, Pontifícia Universidade Católica do Rio de Janeiro, Rio de Janeiro, 2003. 
BRASIL, Constituição (1988). Constituição da República Federativa do Brasil, 1988. Brasília: Senado Federal, Centro Gráfico, 1988. 292 p. Disponível em: <http://www.senado.gov/ legbras>. Acesso em: 5 fev. 2012.

CAMARGO, J. M. Políticas sociais no Brasil: Prioridades erradas, incentivos perversos. São Paulo em Perspectiva, v.18, n. 2, p. 68-77, 2004.

CAMARGO, J. M.; REIS, M. C. Desemprego: O custo da desinformação. Revista Brasileira de Economia - RBE, Rio de Janeiro, v. 59, n. 3, p. 381-425, 2005.

CAMELO, R. S. Exames curriculares e resultados educacionais: Uma análise do Exame Nacional do Ensino Médio. 2010. 148 f. Dissertação (Mestrado em economia) - Fundação Getúlio Vargas, São Paulo, 2010.

CHAHAD, J. P. Z. As transformações no mundo do trabalho e o futuro do seguro-desemprego no Brasil: Elementos a serem considerados num programa moderno. In: ENCONTRO NACIONAL DE ESTUDOS DO TRABALHO, 6., 1999, Rio de Janeiro. Anais... Rio de Janeiro: ABET. p. 20-35, 1999.

CHAHAD, J. P. Z. O seguro-desemprego no contexto do sistema público de emprego e o seu papel no combate à pobreza no caso brasileiro. In: Desigualdade e Pobreza no Brasil. Cap. 20. São Paulo, USP, 2003.

Do MONTE, P. A.; ARAÚJO JUNIOR, I. T; PEREIRA, M. L. O custo salarial da duração do desemprego para o trabalhador. Revista Nova Economia, UFMG, v. 19, n. 3, 2009.

FITZGERALD, J. T. An introduction to the search Theory of Unemployment. Economic Review, 1998. Disponível em: <http://clevelandfed.org/research/review>. Acesso em: 10 mar. 2013.

LEE, D. S.; LEMIEUX, T. Regression Discontinuity designs in economics. Journal of Economic Literature, n. 2, p. 281-355, 2010.

MARINHO, D. N. C.; BALESTRO, M. V.; WALTER, M. I. M. T. Políticas públicas de emprego no Brasil: Avaliação externa do Programa Seguro-Desemprego. Brasília: Verbis, 2010.

MINCER, J. Schooling, experience and earnings. New York: Columbia University Press, 1974. POLLAK, A. Optimal Unemployment Insurance. Mohr Siebeck Tübingen, Alemanha, 2007.

TEIXEIRA, G. S.; BALBINOTTO NETO. Risco moral e seguridade social: O caso do Programa Seguro-Desemprego. ANPEC, 2010. Disponível em: <http://www.anpec.org.br/.../000-269511dd1c3829e1163e12bcb7cf08a6.pdf >. Acesso em: 13 mar. 2013.

\section{Sobre os autores}

Gibran Teixeira-gsteixeira2000@yahoo.com.br

Programa de Pós-Graduação em Economia Aplicada - PPGE/FURG, Universidade Federal do Rio Grande - FURG, Rio Grande, RS.

Giácomo Balbinotto Neto - giacomo.balbinotto@ufrgs.br

Universidade Federal do Rio Grande do Sul - UFRGS, Porto Alegre, RS.

\section{Sobre 0 artigo}

Recebido em 28 de novembro de 2013. Aprovado em 13 de outubro de 2015. 


\section{Apêndices}

\section{Apêndice 1}

Tabela A1 Descrição da amostra

\begin{tabular}{|c|c|c|c|c|c|c|c|}
\hline \multirow{2}{*}{\multicolumn{2}{|c|}{ Características* }} & \multicolumn{3}{|c|}{ Tratados } & \multicolumn{3}{|c|}{ Controles } \\
\hline & & \multirow{2}{*}{$\begin{array}{r}\text { Média } \\
(\mathbf{R} \$) \\
619,98\end{array}$} & \multirow{2}{*}{$\begin{array}{r}\begin{array}{r}\text { Coef. } \\
\text { Variação }\end{array} \\
64,33\end{array}$} & \multirow{2}{*}{$\begin{array}{r}\begin{array}{r}\mathbf{N}^{0} \\
\text { Obss. }\end{array} \\
19\end{array}$} & \multirow{2}{*}{$\begin{array}{r}\text { Média } \\
\text { (R\$) } \\
775,17\end{array}$} & \multirow{2}{*}{$\begin{array}{r}\begin{array}{r}\text { Coef. } \\
\text { Variação }\end{array} \\
70,45\end{array}$} & \multirow{2}{*}{$\begin{array}{r}\begin{array}{r}\mathbf{N}^{\circ} \\
\text { Obs. }\end{array} \\
116\end{array}$} \\
\hline \multirow{4}{*}{ Escolaridade } & Básico & & & & & & \\
\hline & Fundamental & 862,74 & 65,59 & 104 & 769,71 & 72,67 & 901 \\
\hline & Médio & 883,45 & 67,48 & 144 & 790,14 & 79,86 & 1.228 \\
\hline & Superior & $1.658,26$ & 100,87 & 41 & $1.908,79$ & 92,56 & 279 \\
\hline \multirow{5}{*}{ Região } & Norte & 789,97 & 70,05 & 45 & 779,89 & 81,45 & 202 \\
\hline & Nordeste & 756,58 & 86,11 & 92 & 816,53 & 101,24 & 567 \\
\hline & Centro-0este & $1.309,92$ & 115,32 & 125 & 870,15 & 109,23 & 1.110 \\
\hline & Sudeste & 974,35 & 82,67 & 11 & 893,66 & 99,26 & 114 \\
\hline & Sul & $1.002,31$ & 121,80 & 35 & 873,85 & 94,74 & 531 \\
\hline \multirow{5}{*}{ Faixa etária } & $15-25$ anos & 717,50 & 53,63 & 91 & 687,38 & 69,62 & 830 \\
\hline & 26-35 anos & 924,83 & 85,93 & 105 & 909,43 & 97,73 & 931 \\
\hline & 36-45anos & $1.100,83$ & 113,53 & 63 & 958,90 & 105,95 & 493 \\
\hline & $46-55$ anos & 951,60 & 89,11 & 40 & $1.027,91$ & 109,65 & 229 \\
\hline & 56-70 anos & 799,82 & 58,69 & 9 & $1.237,16$ & 86,18 & 41 \\
\hline \multirow{2}{*}{ Gênero } & Masculino & 916,53 & 93,53 & 229 & 946,84 & 98,93 & 1.624 \\
\hline & Feminino & 848,23 & 88,00 & 79 & 707,17 & 88,18 & 900 \\
\hline \multirow{2}{*}{ Posição } & Chefe & 972,17 & 100,18 & 167 & 948,84 & 99,30 & 1.258 \\
\hline & Cônjuge & 921,96 & 90,54 & 53 & 851,30 & 111,37 & 507 \\
\hline Familiar & Filho & 748,70 & 55,28 & 88 & 724,77 & 73,61 & 759 \\
\hline \multirow{2}{*}{ Emprego } & Formal & 904,71 & 86,07 & 238 & 883,51 & 87,87 & 2.109 \\
\hline & Informal & 844,02 & 115,48 & 70 & 626,39 & 98,64 & 415 \\
\hline \multirow{3}{*}{ Cor } & Branca & $1.128,34$ & 96,42 & 135 & 984,13 & 104,73 & 1.181 \\
\hline & Parda & 704,24 & 66,93 & 136 & 724,81 & 72,72 & 1.065 \\
\hline & Demais cores & 737,59 & 55,13 & 37 & 873,02 & 103,62 & 278 \\
\hline \multirow{5}{*}{$\begin{array}{l}\text { Setor } \\
\text { Atividades }\end{array}$} & Agrícola & 564,52 & 37,91 & 15 & 641,99 & 40,68 & 165 \\
\hline & C. Civil & 839,05 & 64,64 & 37 & 841,45 & 82,76 & 325 \\
\hline & Comércio & 949,17 & 92,74 & 86 & 763,93 & 81,75 & 608 \\
\hline & Transporte & 848,36 & 65,03 & 24 & $1.006,17$ & 86,53 & 147 \\
\hline & Público & $1.009,98$ & 56,93 & 13 & $1.299,14$ & 125,74 & 70 \\
\hline
\end{tabular}




\begin{tabular}{l|rr|r|r|r|r|r}
\hline \multirow{2}{*}{ Características* } & \multicolumn{6}{|c|}{ Tratados } & \multicolumn{2}{|c}{ Controles } \\
\cline { 3 - 8 } & & $\begin{array}{r}\text { Média } \\
\text { (R\$) }\end{array}$ & $\begin{array}{r}\text { Coef. } \\
\text { Variação }\end{array}$ & $\begin{array}{r}\mathbf{N} \\
\text { Obs. }\end{array}$ & $\begin{array}{r}\text { Média } \\
\text { (R\$) }\end{array}$ & $\begin{array}{r}\text { Coef. } \\
\text { Variação }\end{array}$ & $\begin{array}{r}\mathbf{N}^{0} \\
\text { Obs. }\end{array}$ \\
\hline \multirow{2}{*}{$\begin{array}{l}\text { Setor } \\
\text { Atividades }\end{array}$} & Serviços & 836,16 & 126,48 & 49 & 779,38 & 129,28 & 390 \\
\cline { 2 - 8 } & Industrial & 853,42 & 46,49 & 60 & 925,94 & 92,74 & 562 \\
\cline { 2 - 8 } & Outros & $1.239,64$ & 123,89 & 24 & $1.033,37$ & 95,91 & 257 \\
\hline
\end{tabular}

Fonte: Resultados da pesquisa. 


\section{Apêndice 2}

Figura A1 Análise da variável salário de reinserção ( $R$ \$)
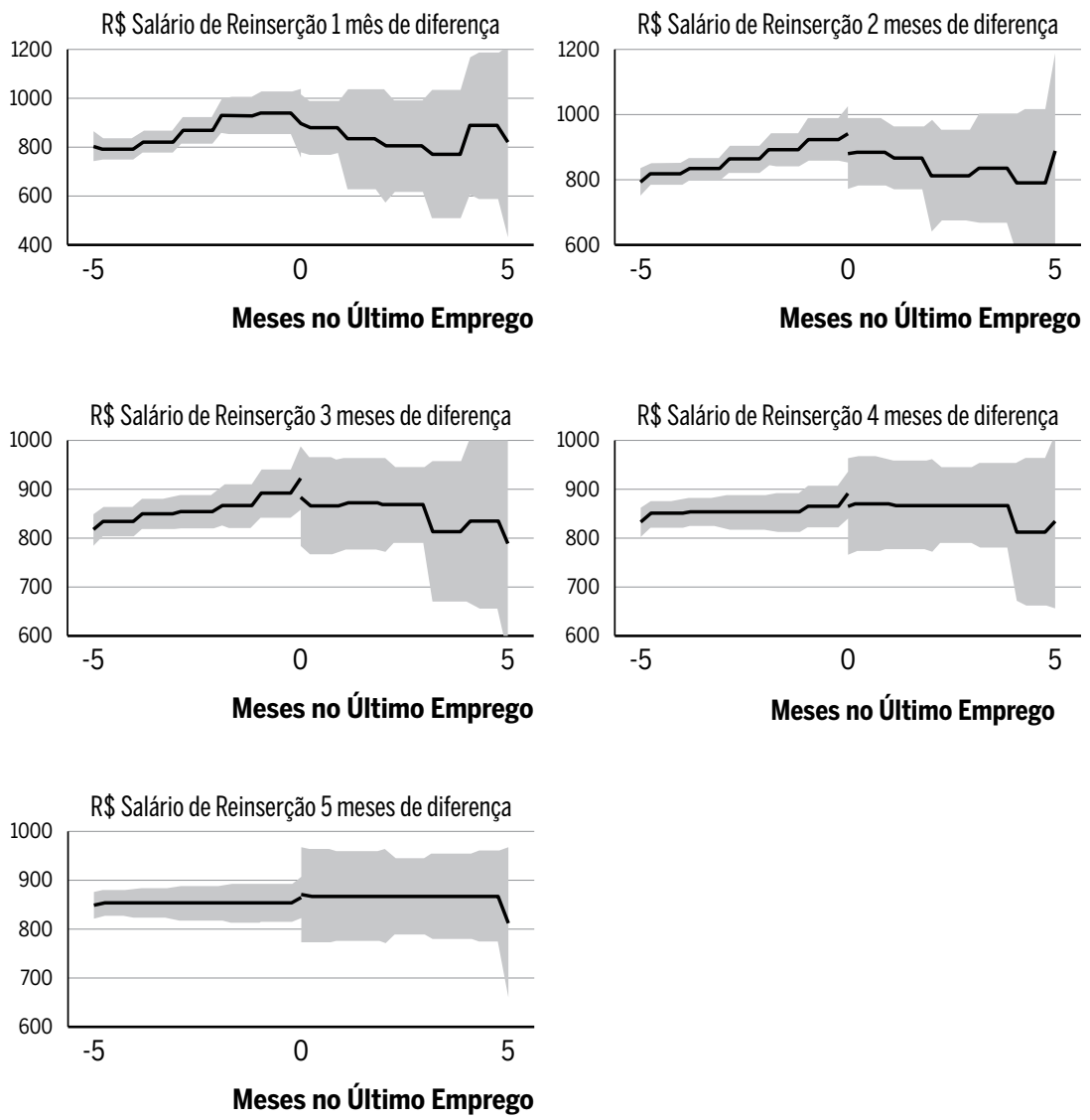

Fonte: Resultados da pesquisa. 


\section{Apêndice 3}

\section{Figura A2 Análise da variável salário de reinserção em Log}
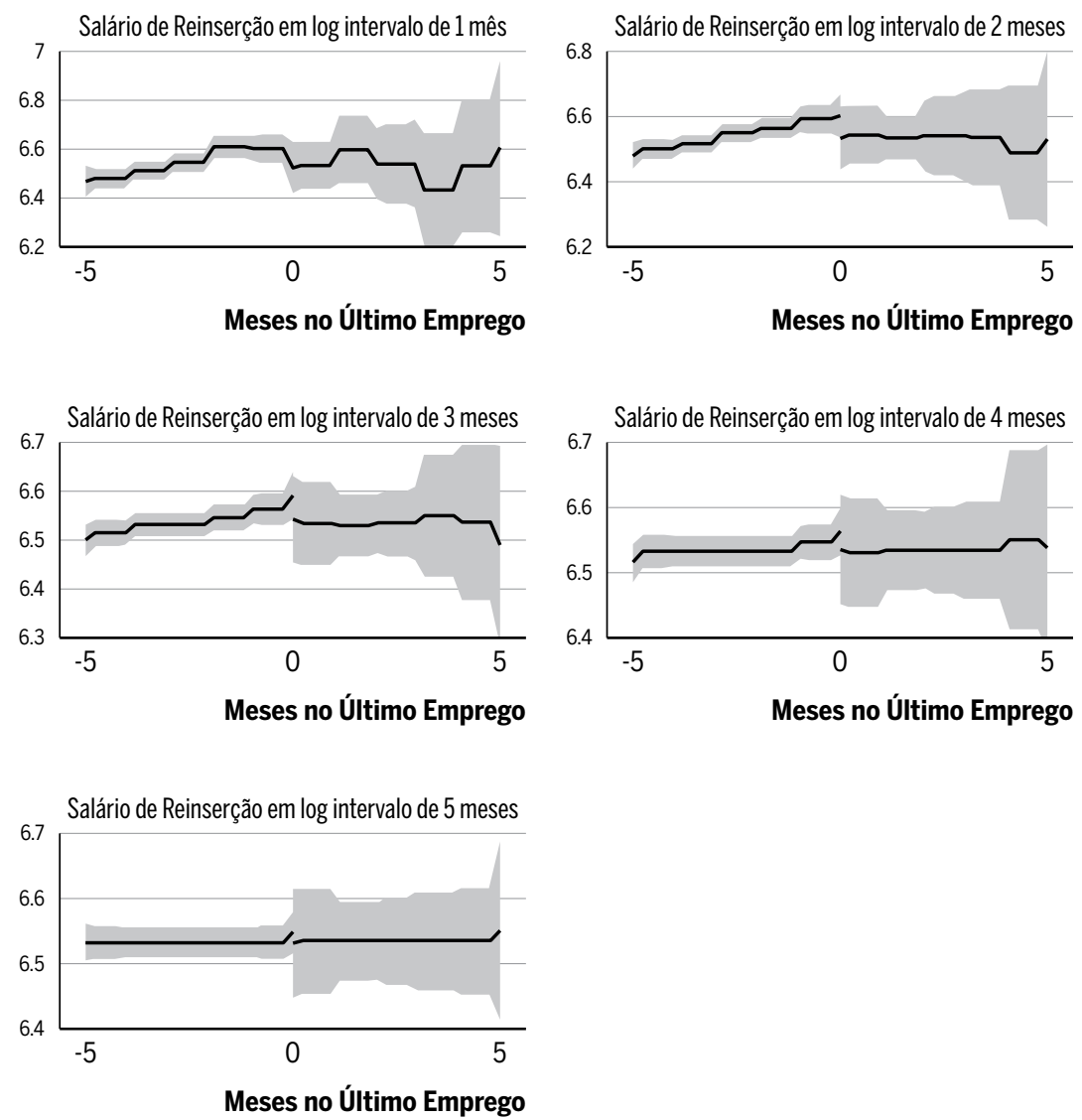

Fonte: Resultados da pesquisa. 
Tabela A2 Falseamento temporal com o cut off sendo 5 meses no emprego anterior

\begin{tabular}{|c|c|c|c|c|c|c|c|c|}
\hline \multirow{4}{*}{ Variáveis } & \multicolumn{2}{|r|}{$\mathrm{TE}=1$} & \multicolumn{2}{|r|}{$\mathrm{TE}<=2$} & \multicolumn{2}{|r|}{$\mathrm{TE}<=3$} & \multicolumn{2}{|r|}{$T E<=4$} \\
\hline & Coef/(dp) & Coef/(dp) & Coef/(dp) & Coef/(dp) & Coef/(dp) & Coef/(dp) & Coef/(dp) & Coef/(dp) \\
\hline & $(n=947)$ & $(n=947)$ & $(n=1.713)$ & $(n=1.713)$ & $(n=2.278)$ & $(n=2.278)$ & $(n=2.803)$ & $(n=2.803)$ \\
\hline & Linear & $\log$ & Linear & $\log$ & Linear & Log & Linear & Log \\
\hline $\mathrm{R}^{2}$ & 0,3114 & 0,3761 & 0,2947 & 0,3434 & 0,2795 & 0,3223 & 0,2803 & 0.3346 \\
\hline Tempo & $-4,150$ & $-0,029$ & $-1,108$ & 0,022 & 47,423 & 0,103 & 73,648 & 0,057 \\
\hline Emprego - TE & $(84,163)$ & $(0,052)$ & $(35,996)$ & $(0,022)$ & $(116,663)$ & $(0,074)$ & $(66,648)$ & $(0,044)$ \\
\hline Recebeu & $-35,162$ & $-0,006$ & $-28,853$ & $-0,057$ & $-89,895$ & $-0,124$ & $-90,373$ & $-0,071$ \\
\hline Seguro - RS & $(118,298)$ & $(0,071)$ & $(84,565)$ & $(0,049)$ & $(118,041)$ & $(0,072)$ & $(86,693)$ & $(0,054)$ \\
\hline TE*RS & - & - & - & - & $\begin{array}{r}-71,013 \\
(185,592)\end{array}$ & $\begin{array}{r}-0,144 \\
(0,120)\end{array}$ & $\begin{array}{r}-134,757 \\
(113,845)\end{array}$ & $\begin{array}{r}-0,099 \\
(0,075)\end{array}$ \\
\hline$(\mathrm{TE})^{2}$ & - & - & - & - & $\begin{array}{r}1,206 \\
(27,241)\end{array}$ & $\begin{array}{r}0,016 \\
(0,018)\end{array}$ & $\begin{array}{r}10,485 \\
(12,326)\end{array}$ & $\begin{array}{r}0,006 \\
(0,008)\end{array}$ \\
\hline Nordeste & $\begin{array}{r}88,882 \\
(71,503)\end{array}$ & $\begin{array}{r}0,042 \\
(0,057)\end{array}$ & $\begin{array}{r}14,039 \\
(70,963)\end{array}$ & $\begin{array}{r}-0,012 \\
(0,047)\end{array}$ & $\begin{array}{r}-1,253 \\
(56,431)\end{array}$ & $\begin{array}{r}-0,015 \\
(0,040)\end{array}$ & $\begin{array}{r}20,421 \\
(49,768)\end{array}$ & $\begin{array}{r}-0,011 \\
(0,036)\end{array}$ \\
\hline Sudeste & $\begin{array}{r}222,206 \\
(66,889)^{*}\end{array}$ & $\begin{array}{r}0,177 \\
(0,053)^{*}\end{array}$ & $\begin{array}{l}129,541 \\
(67,184)\end{array}$ & $\begin{array}{r}0,123 \\
(0,043)^{*}\end{array}$ & $\begin{array}{r}98,212 \\
(52,053)^{*}\end{array}$ & $\begin{array}{r}0,109 \\
(0,036)^{*}\end{array}$ & $\begin{array}{r}114,536 \\
(45,493)^{*}\end{array}$ & $\begin{array}{r}0,116 \\
(0,032)^{*}\end{array}$ \\
\hline Sul & $\begin{array}{r}128,072 \\
(73,559)^{*}\end{array}$ & $\begin{array}{r}0,113 \\
(0,058)^{*}\end{array}$ & $\begin{array}{r}-16,025 \\
(70,714)\end{array}$ & $\begin{array}{r}0,036 \\
(0,047)\end{array}$ & $\begin{array}{r}16,795 \\
(56,987)\end{array}$ & $\begin{array}{r}0,033 \\
(0,041)\end{array}$ & $\begin{array}{r}45,812 \\
(49,555)\end{array}$ & $\begin{array}{r}0,058 \\
(0,036)\end{array}$ \\
\hline Centro-Oeste & $\begin{array}{r}92,083 \\
(101,111)\end{array}$ & $\begin{array}{r}0,141 \\
(0,085)\end{array}$ & $\begin{array}{r}61,665 \\
(80,661)\end{array}$ & $\begin{array}{r}0,124 \\
(0,060)^{*}\end{array}$ & $\begin{array}{r}80,120 \\
(76,017)\end{array}$ & $\begin{array}{r}0,122 \\
(0,057)\end{array}$ & $\begin{array}{r}94,989 \\
(64,545)^{*}\end{array}$ & $\begin{array}{r}0,140 \\
(0,050)^{*}\end{array}$ \\
\hline Homem & $\begin{array}{r}281,398 \\
(63,766)^{*}\end{array}$ & $\begin{array}{r}0,266 \\
(0,039)^{*}\end{array}$ & $\begin{array}{l}316,055 \\
(50,459)\end{array}$ & $\begin{array}{r}0,260 \\
(0,029)^{*}\end{array}$ & $\begin{array}{r}315,613 \\
(41,895)^{*}\end{array}$ & $\begin{array}{r}0,275 \\
(0,025)^{*}\end{array}$ & $\begin{array}{r}296,138 \\
(35,596)^{*}\end{array}$ & $\begin{array}{r}0,226 \\
(0,022)\end{array}$ \\
\hline $\begin{array}{l}\text { Anos de } \\
\text { Estudo }\end{array}$ & - & $\begin{array}{r}0,090 \\
(0,006)^{*}\end{array}$ & & $\begin{array}{r}0,086 \\
(0,005)^{*}\end{array}$ & & $\begin{array}{r}0,079 \\
(0,004)^{*}\end{array}$ & & $\begin{array}{r}0,079 \\
(0,004)^{*}\end{array}$ \\
\hline $\begin{array}{l}\text { Ensino } \\
\text { Fundamental }\end{array}$ & $\begin{array}{r}280,721 \\
(156,451)^{*}\end{array}$ & & $\begin{array}{r}232,634 \\
(101,149)^{*}\end{array}$ & & $\begin{array}{r}199,106 \\
(82,712)^{*}\end{array}$ & & $\begin{array}{r}162,538 \\
(71,822)^{*}\end{array}$ & \\
\hline $\begin{array}{l}\text { Ensino } \\
\text { Médio }\end{array}$ & $\begin{array}{r}545,501 \\
(178,001)^{*}\end{array}$ & & $\begin{array}{r}460,384 \\
(117,466)^{*}\end{array}$ & & $\begin{array}{r}415,147 \\
(96,192)^{*}\end{array}$ & & $\begin{array}{r}378,670 \\
(82,161)^{*}\end{array}$ & \\
\hline $\begin{array}{l}\text { Ensino } \\
\text { Superior }\end{array}$ & $\begin{array}{r}1.627,947 \\
(261,194)^{*}\end{array}$ & & $\begin{array}{r}1.540,111 \\
(177,382)^{*}\end{array}$ & - & $\begin{array}{r}1.398,789 \\
(148,520)^{*}\end{array}$ & & $\begin{array}{r}1.319,982 \\
(130,079)^{*}\end{array}$ & \\
\hline $\begin{array}{l}\text { Experiência } \\
\text { Profissional }\end{array}$ & & $\begin{array}{r}0,022 \\
(0,005)^{*}\end{array}$ & & $\begin{array}{r}0,019 \\
(0,004)^{*}\end{array}$ & & $\begin{array}{r}0,017 \\
(0,003)^{*}\end{array}$ & & $\begin{array}{r}0,018 \\
(0,003)^{*}\end{array}$ \\
\hline $\begin{array}{l}\text { (Experiência } \\
\text { Profissional)2 }\end{array}$ & & $\begin{array}{l}-0,0001 \\
(0,0001)\end{array}$ & & $\begin{array}{r}-0,0001 \\
(0,00009)\end{array}$ & & $\begin{array}{r}-0,0001 \\
(0,00008)\end{array}$ & & $\begin{array}{r}-0,0001 \\
(0,00006)\end{array}$ \\
\hline Carteira & $\begin{array}{r}172,527 \\
(62,920)^{*}\end{array}$ & $\begin{array}{r}0,222 \\
(0,048)^{*}\end{array}$ & $\begin{array}{r}156,718 \\
(48,120)^{*}\end{array}$ & $\begin{array}{r}0,237 \\
(0,036)^{*}\end{array}$ & $\begin{array}{r}121,064 \\
(39,524)^{*}\end{array}$ & $\begin{array}{r}0,221 \\
(0,032)^{*}\end{array}$ & $\begin{array}{r}123,559 \\
(32,893)^{*}\end{array}$ & $\begin{array}{r}0,246 \\
(0,028)\end{array}$ \\
\hline Branca & $\begin{array}{r}111,840 \\
(111,839)\end{array}$ & $\begin{array}{r}0,148 \\
(0,059)^{*}\end{array}$ & $\begin{array}{r}71,849 \\
(73,893)\end{array}$ & $\begin{array}{r}0,123 \\
(0,043)^{*}\end{array}$ & $\begin{array}{r}88,701 \\
(59,892)\end{array}$ & $\begin{array}{r}0,125 \\
(0,036)^{*}\end{array}$ & $\begin{array}{r}60,899 \\
(53,101)\end{array}$ & $\begin{array}{r}0,100 \\
(0,032)^{*}\end{array}$ \\
\hline
\end{tabular}




\begin{tabular}{|c|c|c|c|c|c|c|c|c|}
\hline \multirow{4}{*}{ Variáveis } & \multicolumn{2}{|r|}{$\mathrm{TE}=1$} & \multicolumn{2}{|r|}{$\mathrm{TE}<=2$} & \multicolumn{2}{|r|}{$\mathrm{TE}<=3$} & \multicolumn{2}{|r|}{$\mathrm{TE}<=4$} \\
\hline & Coef/(dp) & Coef/(dp) & Coef/(dp) & Coef/(dp) & Coef/(dp) & Coef/(dp) & Coef/(dp) & Coef/(dp) \\
\hline & $(n=947)$ & $(n=947)$ & $(n=1.713)$ & $(n=1.713)$ & $(n=2.278)$ & $(n=2.278)$ & $(n=2.803)$ & $(n=2.803)$ \\
\hline & Linear & Log & Linear & Log & Linear & Log & Linear & Log \\
\hline Parda & $\begin{array}{r}-47,810 \\
(97,207)\end{array}$ & $\begin{array}{r}-0,011 \\
(0,059)\end{array}$ & $\begin{array}{r}-41,324 \\
(67,208)\end{array}$ & $\begin{array}{r}-0,005 \\
(0,043)\end{array}$ & $\begin{array}{r}-21,152 \\
(54,736)\end{array}$ & $\begin{array}{r}0,003 \\
(0,035)\end{array}$ & $\begin{array}{r}-44,522 \\
(48,994)\end{array}$ & $\begin{array}{r}-0,022 \\
(0,032)\end{array}$ \\
\hline Chefe & $\begin{array}{r}-27,803 \\
(92,773)\end{array}$ & $\begin{array}{r}0,007 \\
(0,051)\end{array}$ & $\begin{array}{r}-57,609 \\
(62,581)\end{array}$ & $\begin{array}{r}-0,017 \\
(0,036)\end{array}$ & $\begin{array}{r}-60,789 \\
(51,132)\end{array}$ & $\begin{array}{r}-0,034 \\
(0,032)\end{array}$ & $\begin{array}{r}-48,657 \\
(44,847)\end{array}$ & $\begin{array}{r}-0,022 \\
(0,028)\end{array}$ \\
\hline Filho & $\begin{array}{r}-183,737 \\
(86,714)^{*}\end{array}$ & $\begin{array}{r}-0,092 \\
(0,052)\end{array}$ & $\begin{array}{r}-184,332 \\
(60.424)^{*}\end{array}$ & $\begin{array}{r}-0,132 \\
(0,039)^{*}\end{array}$ & $\begin{array}{r}-191,706 \\
(48,918)^{*}\end{array}$ & $\begin{array}{r}-0,134 \\
(0,033)^{*}\end{array}$ & $\begin{array}{r}-170,261 \\
(42,601)^{*}\end{array}$ & $\begin{array}{r}-0,120 \\
(0,030)^{*}\end{array}$ \\
\hline $\begin{array}{l}\text { De } 26 \text { até } \\
35 \text { anos }\end{array}$ & $\begin{array}{r}144,646 \\
(45,902)^{*}\end{array}$ & & $\begin{array}{r}131,071 \\
(34.026)^{*}\end{array}$ & & $\begin{array}{r}113,805 \\
(28,391)^{*}\end{array}$ & & $\begin{array}{r}137,243 \\
(25,510)^{*}\end{array}$ & \\
\hline $\begin{array}{l}\text { De } 36 \text { até } \\
45 \text { anos }\end{array}$ & $\begin{array}{r}335,807 \\
(84,479)^{*}\end{array}$ & & $\begin{array}{r}273,584 \\
(58,654)^{*}\end{array}$ & & $\begin{array}{r}243,264 \\
(49,685)^{*}\end{array}$ & & $\begin{array}{r}247,699 \\
(42,861)^{*}\end{array}$ & \\
\hline $\begin{array}{l}\text { De } 45 \text { até } \\
55 \text { anos }\end{array}$ & $\begin{array}{r}671,579 \\
(200,800)^{*} \\
\end{array}$ & & $\begin{array}{r}499,696 \\
(121,806)^{*}\end{array}$ & & $\begin{array}{r}429,137 \\
(96,963)^{*}\end{array}$ & & $\begin{array}{r}412,906 \\
(79,740)^{*}\end{array}$ & \\
\hline $\begin{array}{l}\text { Acima de } \\
55 \text { anos }\end{array}$ & $\begin{array}{r}384,368 \\
(194,354)^{*}\end{array}$ & - & $\begin{array}{r}774,475 \\
(246,445)^{*}\end{array}$ & . & $\begin{array}{r}623,502 \\
(194,666)^{*}\end{array}$ & & $\begin{array}{r}558,692 \\
(156,200)^{*}\end{array}$ & \\
\hline Agrícola & $\begin{array}{r}-33.889 \\
(89,251)\end{array}$ & $\begin{array}{r}0,062 \\
(0,081)\end{array}$ & $\begin{array}{r}-75,400 \\
(64,473)\end{array}$ & $\begin{array}{r}-0,026 \\
(0,057)\end{array}$ & $\begin{array}{r}-60,178 \\
(49,103)\end{array}$ & $\begin{array}{r}-0,040 \\
(0,045)\end{array}$ & $\begin{array}{r}-70,495 \\
(44,427)^{*}\end{array}$ & $\begin{array}{r}-0,056 \\
(0,042)\end{array}$ \\
\hline Indústria & $\begin{array}{r}64.378 \\
(102,506)\end{array}$ & $\begin{array}{r}-0,034 \\
(0,060)\end{array}$ & $\begin{array}{r}24,556 \\
(75,754)\end{array}$ & $\begin{array}{r}-0,064 \\
(0,046)\end{array}$ & $\begin{array}{r}43,073 \\
(58,363)\end{array}$ & $\begin{array}{r}-0,042 \\
(0,038)\end{array}$ & $\begin{array}{r}34,444 \\
(50,874)\end{array}$ & $\begin{array}{r}-0,055 \\
(0,034)\end{array}$ \\
\hline Comércio & $\begin{array}{r}-67,205 \\
(90,330)\end{array}$ & $\begin{array}{r}-0,098 \\
(0,060)\end{array}$ & $\begin{array}{r}-83,312 \\
(68,670)\end{array}$ & $\begin{array}{r}-0,136 \\
(0,046)^{*}\end{array}$ & $\begin{array}{r}-38,458 \\
(53,481)\end{array}$ & $\begin{array}{r}-0,101 \\
(0,038)^{*}\end{array}$ & $\begin{array}{r}-62,052 \\
(45,982)\end{array}$ & $\begin{array}{r}-0,132 \\
(0,034)^{*}\end{array}$ \\
\hline Transporte & $\begin{array}{r}-21,666 \\
(156,97)\end{array}$ & $\begin{array}{r}-0,012 \\
(0,079)\end{array}$ & $\begin{array}{r}-44,303 \\
(102,421)\end{array}$ & $\begin{array}{r}-0,034 \\
(0,058)\end{array}$ & $\begin{array}{r}4,652 \\
(83,092)\end{array}$ & $\begin{array}{r}0,017 \\
(0,050)\end{array}$ & $\begin{array}{r}5,395 \\
(69,850)\end{array}$ & $\begin{array}{r}-0,004 \\
(0,046)\end{array}$ \\
\hline $\begin{array}{l}\text { Adm. } \\
\text { Pública }\end{array}$ & $\begin{array}{r}-64,362 \\
(248.913)\end{array}$ & $\begin{array}{r}-0,106 \\
(0,133)\end{array}$ & $\begin{array}{r}-111,048 \\
(180,100)\end{array}$ & $\begin{array}{r}-0,118 \\
(0,097)\end{array}$ & $\begin{array}{r}-54,991 \\
(149,108)\end{array}$ & $\begin{array}{r}-0,027 \\
(0,086)\end{array}$ & $\begin{array}{r}-59,139 \\
(129,143)\end{array}$ & $\begin{array}{r}-0,060 \\
(0,042)\end{array}$ \\
\hline Serviços & $\begin{array}{r}-192,722 \\
(91.865)^{*}\end{array}$ & $\begin{array}{r}-0,220 \\
(0,069)^{*}\end{array}$ & $\begin{array}{r}-121,973 \\
(85,416)\end{array}$ & $\begin{array}{r}-0,201 \\
(0,055)^{*}\end{array}$ & $\begin{array}{r}-88,307 \\
(67,590)\end{array}$ & $\begin{array}{r}-0,177 \\
(0,046)^{*}\end{array}$ & $\begin{array}{r}-122,543 \\
(56,827)^{*}\end{array}$ & $\begin{array}{r}-0,206 \\
(0,040)^{*}\end{array}$ \\
\hline $\begin{array}{l}\text { Outras } \\
\text { Atividades }\end{array}$ & $\begin{array}{r}36.233 \\
(130,466)\end{array}$ & $\begin{array}{r}-0,026 \\
(0,073)\end{array}$ & $\begin{array}{r}-26,556 \\
(95,683)\end{array}$ & $\begin{array}{r}-0,092 \\
(0,056)\end{array}$ & $\begin{array}{r}13,587 \\
(75,094)\end{array}$ & $\begin{array}{r}-0,056 \\
(0,048)\end{array}$ & $\begin{array}{r}22,756 \\
(63,312)\end{array}$ & $\begin{array}{r}-0,060 \\
(0,042)\end{array}$ \\
\hline 2009 & $\begin{array}{r}3,694 \\
(54,724)\end{array}$ & $\begin{array}{r}0,044 \\
(0,038)\end{array}$ & $\begin{array}{r}19,985 \\
(38,861)\end{array}$ & $\begin{array}{r}0,029 \\
(0,027)\end{array}$ & $\begin{array}{r}35,139 \\
(31,708)\end{array}$ & $0,034(0,023)$ & $\begin{array}{r}52,041 \\
(27,331)\end{array}$ & $\begin{array}{r}0,052 \\
(0,020)^{*}\end{array}$ \\
\hline 2008 & $\begin{array}{r}115,038 \\
(83,874)\end{array}$ & $0,091(0,049)$ & $\begin{array}{r}103,372 \\
(62,303)\end{array}$ & $\begin{array}{r}0,054 \\
(0,036)\end{array}$ & $\begin{array}{r}96,378 \\
(49,988)^{*}\end{array}$ & $\begin{array}{r}0,046 \\
(0,031)\end{array}$ & $\begin{array}{r}95,647 \\
(43,009)^{*}\end{array}$ & $\begin{array}{r}0,050 \\
(0,027)\end{array}$ \\
\hline
\end{tabular}

Fonte: Resultados da pesquisa.

* Coeficientes significativos a $10 \%$. 
Tabela A3 Falseamento temporal com o cut off sendo 4 meses no emprego anterior

\begin{tabular}{|c|c|c|c|c|c|c|c|c|}
\hline \multirow{4}{*}{ Variáveis } & \multicolumn{2}{|r|}{$\mathrm{TE}=1$} & \multicolumn{2}{|r|}{$\mathrm{TE}<=2$} & \multicolumn{2}{|r|}{$\mathrm{TE}<=3$} & \multicolumn{2}{|r|}{$\mathrm{TE}<=4$} \\
\hline & $\beta /(d p)$ & $\beta /(d p)$ & $\beta /(\mathrm{dp})$ & $\beta /(\mathrm{dp})$ & $\beta /(d p)$ & $\beta /(d p)$ & $\beta /(d p)$ & $\beta /(d p)$ \\
\hline & $(n=1.486)$ & $(n=1.486)$ & $(n=2.217)$ & $(n=2.217)$ & $(n=2.751)$ & $(n=2.751)$ & $(n=2.782)$ & $(n=2.782)$ \\
\hline & Linear & Log & Linear & $\log$ & Linear & Log & Linear & Log \\
\hline $\mathrm{R}^{2}$ & $31 \%$ & $35 \%$ & $29 \%$ & $32 \%$ & $28 \%$ & $34 \%$ & $28 \%$ & $34 \%$ \\
\hline Tempo & $-30,265$ & $-0,027$ & 72,109 & 0.0225 & 54.911 & 0.0622 & 52,815 & 0.0622 \\
\hline Emprego - TE & $(56,742)$ & $(0,033)$ & $(160,594)$ & (0.1098) & (95.109) & $(0.0616)$ & $(3,127)^{*}$ & $(0.0616)$ \\
\hline Recebeu & 58.474 & 0,075 & $-34,329$ & 0.0247 & 3.034 & 0.0019 & $-4,351$ & 0.0019 \\
\hline Seguro-RS & $(90,657)$ & $(0,053)$ & $(114,668)$ & $(0,0791)$ & (83.281) & $(0.0551)$ & $(3,010)^{*}$ & $(0.0551)$ \\
\hline$T F * D S$ & & & $-114,264$ & -0.0520 & -115.384 & -0.1150 & $-104,106$ & -0.1150 \\
\hline II $\mathrm{kJ}$ & - & - & $(255,406)$ & $(0.1700)$ & (147.883) & $(0.0970)$ & $(5,478)^{*}$ & $(0.0970)$ \\
\hline & & & 6,961 & -0.0019 & 10.925 & 0.0123 & 9.811 & 0.0123 \\
\hline$(\text { IIt) })^{2}$ & - & - & (51,774) & $(0.0354)$ & (23.612) & $(0.0152)$ & $(0.756)^{*}$ & $(0.0152)$ \\
\hline Nordecto & 24,931 & $-0,001$ & 3,308 & -0.0094 & 22.5588 & -0.0151 & $-5,157$ & -0.0151 \\
\hline Nordeste & $(81,636)$ & $(0,051)$ & (60.734) & $(0.0407)$ & (53.2981) & $(0.0362)$ & $(3,057)^{*}$ & $(0.0362)$ \\
\hline Sudecto & 114,089 & 0,108 & 102.924 & 0.1153 & 116.500 & 0.1130 & 89.599 & 0.1130 \\
\hline sulesste & $(77,497)$ & $(0,048)^{*}$ & (57.805) & $(0.0372)^{*}$ & $(50.795)^{*}$ & $(0.0327)^{*}$ & $(2.777)^{*}$ & $(0.0327)^{*}$ \\
\hline Sul & $-15,571$ & 0,013 & 21,899 & 0.0358 & 48.789 & 0.0542 & -1.158 & 0.0542 \\
\hline JuI & $(87,300)$ & $(0,051)$ & $(66,218)$ & $(0.0418)$ & (57.664) & $(0.0366)$ & (2.902) & $(0.0366)$ \\
\hline Centro-Deste & 41,825 & 0,111 & 84,958 & 0.1338 & 98.800 & 0.1396 & 49.446 & 0.1396 \\
\hline & $(119,720)$ & $(0.065)^{*}$ & $(93,654)$ & $(0.0586)^{*}$ & (81.041) & $(0.0508)^{*}$ & $(3.645)^{*}$ & $(0.0508)$ \\
\hline Homom & $311,743^{*}$ & 0,266 & 310,165 & 0.2749 & 295.400 & 0.2694 & 326.079 & 0.2694 \\
\hline numilinI & $(50,677)$ & $(0,031)^{*}$ & $(39,245)^{*}$ & $(0.0262)^{*}$ & $(33.628)^{*}$ & $(0.0230)^{*}$ & $(1,666)^{*}$ & $(0.0230)^{*}$ \\
\hline Anos de & & 0,088 & & 0.0799 & & 0.0792 & & 0.0792 \\
\hline Estudo & & $(0,005)^{*}$ & & $(0.0048)^{*}$ & & $(0.0042)^{*}$ & & $(0.0042)^{*}$ \\
\hline Ensino & 268,757 & & 196,685 & & 157.196 & & 156,020 & \\
\hline Fundamental & $(111,058)^{*}$ & & $(85,657)^{*}$ & & $(74.731)^{*}$ & & $(3,041)^{*}$ & \\
\hline Ensino & 494,290 & & 413,980 & & 374.354 & & 361,960 & \\
\hline Médio & $(114,250)^{*}$ & & $(88,745)^{*}$ & & $(77.095)^{*}$ & & $(3,450)^{*}$ & \\
\hline Ensino & $1.629,240$ & & $1.433,391$ & & 1327.351 & & $1.309,366$ & \\
\hline Superior & $(125,438)^{*}$ & & $(97.690)$ & & $(85.189)^{*}$ & & $(5,772)^{*}$ & \\
\hline Experiência & & 0,018 & & 0.0177 & & 0.0177 & & 0.0177 \\
\hline Profissional & & $(0,004)^{*}$ & & $(0.0036)^{*}$ & & $(0.0032)^{*}$ & & $(0.0032)^{*}$ \\
\hline (Experiência & & $-0,0001$ & & -0.0001 & & -0.0001 & & $-0.0001^{*}$ \\
\hline Profissional) $^{2}$ & & $(0.0001)$ & & $(0.0001)$ & & $(0.0001)$ & & $(0,0001)$ \\
\hline Ontrim & 179,824 & 0,240 & 125,207 & 0.2293 & 129.282 & 0.2518 & 149,305 & 0.2518 \\
\hline Galteria & $(55,526)^{*}$ & $(0,039)^{*}$ & $(41,537)^{*}$ & $(0.0328)^{*}$ & $(35.111)^{*}$ & $(0.0284)^{*}$ & $(1,433)^{*}$ & $(0.0284)^{*}$ \\
\hline Pronca & 42,753 & 0,086 & 77,163 & 0.1202 & 50.8327 & 0.0986 & 44,647 & 0.0986 \\
\hline Dialla & $(65,697)$ & $(0,001)^{*}$ & $(51,584)$ & $(0.0370)^{*}$ & (45.0378) & $(0.0334)^{*}$ & $(2,584)^{*}$ & $(0.0334)^{*}$ \\
\hline
\end{tabular}




\begin{tabular}{|c|c|c|c|c|c|c|c|c|}
\hline \multirow{4}{*}{ Variáveis } & \multicolumn{2}{|r|}{$\mathrm{TE}=1$} & \multicolumn{2}{|r|}{$\mathrm{TE}<=2$} & \multicolumn{2}{|r|}{$\mathrm{TE}<=3$} & \multicolumn{2}{|r|}{$\mathrm{TE}<=4$} \\
\hline & $\beta /(d p)$ & $\beta /(d p)$ & $\beta /(d p)$ & $\beta /(d p)$ & $\beta /(d p)$ & $\beta /(d p)$ & $\beta /(d p)$ & $\beta /(d p)$ \\
\hline & $(n=1.486)$ & $(n=1.486)$ & $(n=2.217)$ & $(n=2.217)$ & $(n=2.751)$ & $(n=2.751)$ & $(n=2.782)$ & $(n=2.782)$ \\
\hline & Linear & $\log$ & Linear & $\log$ & Linear & $\log$ & Linear & Log \\
\hline Parda & $\begin{array}{r}-61,411 \\
(65,372)\end{array}$ & $\begin{array}{r}-0,024 \\
(0,002)^{*}\end{array}$ & $\begin{array}{r}-30,865 \\
(51,258)\end{array}$ & $\begin{array}{r}-0.0023 \\
(0.0367)\end{array}$ & $\begin{array}{r}-50.3839 \\
(44.6725)\end{array}$ & $\begin{array}{r}-0.0244 \\
(0.0330)\end{array}$ & $\begin{array}{r}-56,898 \\
(2,397)^{*}\end{array}$ & $\begin{array}{r}-0.0244 \\
(0.0330)\end{array}$ \\
\hline Chefe & $\begin{array}{r}-67,694 \\
(56,588)\end{array}$ & $\begin{array}{l}-0,028 \\
(0,038)\end{array}$ & $\begin{array}{r}-58,662 \\
(44,143)\end{array}$ & $\begin{array}{r}-0.0341 \\
(0.0328)\end{array}$ & $\begin{array}{l}-49.8443 \\
(38.2718)\end{array}$ & $\begin{array}{r}-0.0200 \\
(0.0291)\end{array}$ & $\begin{array}{r}-73,305 \\
(2,158)^{*}\end{array}$ & $\begin{array}{r}-0.0200 \\
(0.0291)\end{array}$ \\
\hline Filho & $\begin{array}{r}-191,149 \\
(65,770)^{*}\end{array}$ & $\begin{array}{r}-0,138 \\
(0,041)^{*}\end{array}$ & $\begin{array}{r}-189,422 \\
(50,455)^{*}\end{array}$ & $\begin{array}{r}-0.1288 \\
(0.0343)^{*}\end{array}$ & $\begin{array}{r}-168.484 \\
(43.528)^{*}\end{array}$ & $\begin{array}{r}-0.1193 \\
(0.0305)^{*}\end{array}$ & $\begin{array}{l}-184,365 \\
(2,033)^{*}\end{array}$ & $\begin{array}{r}-0.1193 \\
(0.0305)^{*}\end{array}$ \\
\hline $\begin{array}{l}\text { De } 26 \text { até } \\
35 \text { anos }\end{array}$ & $\begin{array}{r}129,604 \\
(52,575)^{*}\end{array}$ & - & $\begin{array}{r}114,570 \\
(40,494)^{*}\end{array}$ & - & $\begin{array}{r}136.955 \\
(35.013)^{*}\end{array}$ & - & $\begin{array}{l}132,793 \\
(1,145)^{*}\end{array}$ & \\
\hline $\begin{array}{l}\text { De } 36 \text { até } \\
45 \text { anos }\end{array}$ & $\begin{array}{r}279,027 \\
(65,720)^{*}\end{array}$ & - & $\begin{array}{r}245,756 \\
(50,976)^{*}\end{array}$ & & $\begin{array}{r}247.680 \\
(43.792)^{*}\end{array}$ & & $\begin{array}{c}248,777 \\
(1,945)^{*}\end{array}$ & \\
\hline $\begin{array}{l}\text { De } 45 \text { até } \\
55 \text { anos }\end{array}$ & $\begin{array}{r}550,004 \\
(89,622)^{*}\end{array}$ & - & $\begin{array}{r}441,714 \\
(69,554)^{*}\end{array}$ & - & $\begin{array}{r}407.334 \\
(59.307)^{*}\end{array}$ & 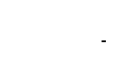 & $\begin{array}{c}392,513 \\
(3,436)^{*}\end{array}$ & \\
\hline $\begin{array}{l}\text { Acima de } \\
55 \text { anos }\end{array}$ & $\begin{array}{r}872,955 \\
(182,720)^{*}\end{array}$ & - & $\begin{array}{r}596,029 \\
(137,009)^{*}\end{array}$ & & $\begin{array}{r}572.943 \\
(115.297)^{*}\end{array}$ & & $\begin{array}{l}493,400 \\
(6,363)^{*}\end{array}$ & \\
\hline Agricola & $\begin{array}{r}-67,018 \\
(98,195)\end{array}$ & $\begin{array}{r}0,020 \\
(0,058)\end{array}$ & $\begin{array}{r}-53,887 \\
(74,986)\end{array}$ & $\begin{array}{c}-0.0388 \\
(0.0462)\end{array}$ & $\begin{array}{r}-65.768 \\
(66.574)\end{array}$ & $\begin{array}{r}-0.0525 \\
(0.0429)\end{array}$ & $\begin{array}{r}-60,777 \\
(1,966)^{*}\end{array}$ & $\begin{array}{r}-0.0525 \\
(0.0429)\end{array}$ \\
\hline Indústria & $\begin{array}{r}36,810 \\
(72,390)\end{array}$ & $\begin{array}{r}-0,073 \\
(0,049)\end{array}$ & $\begin{array}{r}53,602 \\
(55,812)\end{array}$ & $\begin{array}{r}-0.0366 \\
(0.0388)\end{array}$ & $\begin{array}{r}37.430 \\
(48.333)\end{array}$ & $\begin{array}{r}-0.0564 \\
(0.0348)\end{array}$ & $\begin{array}{r}51,952 \\
(2,339)^{*}\end{array}$ & $\begin{array}{r}-0.0564 \\
(0.0348)\end{array}$ \\
\hline Comércio & $\begin{array}{l}-88,360 \\
(75,341)\end{array}$ & $\begin{array}{r}0,152 \\
(0,048)^{*}\end{array}$ & $\begin{array}{r}-37.5631 \\
(57.5571)\end{array}$ & $\begin{array}{r}-0.097 \\
(0.039)^{*}\end{array}$ & $\begin{array}{r}-61.737 \\
(49.584)\end{array}$ & $\begin{array}{r}-0.1299 \\
(0.0350)^{*}\end{array}$ & $\begin{array}{r}-58,133 \\
(2,104)^{*}\end{array}$ & $\begin{array}{r}-0.1299 \\
(0.0350)^{*}\end{array}$ \\
\hline Transporte & $\begin{array}{r}-38,307 \\
(99.961)\end{array}$ & $\begin{array}{r}-0,039 \\
(0,061)\end{array}$ & $\begin{array}{r}10.9265 \\
(77.5338)\end{array}$ & $\begin{array}{r}0.022 \\
(0.051)\end{array}$ & $\begin{array}{r}8.116 \\
(66.311)\end{array}$ & $\begin{array}{r}-0.0019 \\
(0.0468)\end{array}$ & $\begin{array}{r}45,970 \\
(3,186)^{*}\end{array}$ & $\begin{array}{r}-0.0019 \\
(0.0468)\end{array}$ \\
\hline Serviços & $\begin{array}{r}-117,480 \\
(87,514)\end{array}$ & $\begin{array}{r}-0,187 \\
(0,058)^{*}\end{array}$ & $\begin{array}{r}-88.5598 \\
(67.2081)\end{array}$ & $\begin{array}{r}-0.1736 \\
(0.0468)^{*}\end{array}$ & $\begin{array}{r}-117.311 \\
(57.535)^{*}\end{array}$ & $\begin{array}{r}-0.1979 \\
(0.0408)^{*}\end{array}$ & $\begin{array}{r}-80,962 \\
(2,591)^{*}\end{array}$ & $\begin{array}{r}-0.1979 \\
(0.0408)^{*}\end{array}$ \\
\hline Adm.Pública & $\begin{array}{r}-66,713 \\
(157,331)\end{array}$ & $\begin{array}{r}-0,120 \\
(0,103)\end{array}$ & $\begin{array}{r}-34.6798 \\
(120.5294)\end{array}$ & $\begin{array}{r}-0.0107 \\
(0.0901)\end{array}$ & $\begin{array}{r}-57.528 \\
(103.933)\end{array}$ & $\begin{array}{r}-0.0313 \\
(0.0758)\end{array}$ & $\begin{array}{r}28,154 \\
(5,793)^{*}\end{array}$ & $\begin{array}{r}-0.0313 \\
(0.0758)\end{array}$ \\
\hline $\begin{array}{l}\text { Outras } \\
\text { Atividades }\end{array}$ & $\begin{array}{r}-85,877 \\
(89.345)\end{array}$ & $\begin{array}{r}-0,123 \\
(0,057)^{*}\end{array}$ & $\begin{array}{r}21.2262 \\
(68.2083)\end{array}$ & $\begin{array}{r}-0.0430 \\
(0.0488)\end{array}$ & $\begin{array}{r}28.097 \\
(57.961)\end{array}$ & $\begin{array}{r}-0.0531 \\
(0.0432)\end{array}$ & $\begin{array}{r}46.358 \\
(2,881)^{*}\end{array}$ & $\begin{array}{r}-0.0531 \\
(0.0432) \\
\end{array}$ \\
\hline 2009 & $\begin{array}{r}40,996 \\
(46,142)\end{array}$ & $\begin{array}{r}0,033 \\
(0,028)\end{array}$ & $\begin{array}{r}34.5704 \\
(36.1641)\end{array}$ & $\begin{array}{r}0.0353 \\
(0.0240)\end{array}$ & $\begin{array}{r}50.088 \\
(31.015)\end{array}$ & $\begin{array}{r}0.0521 \\
(0.0212)^{*}\end{array}$ & $\begin{array}{r}57,590 \\
(1,182)^{*}\end{array}$ & $\begin{array}{r}0.0521 \\
(0.0212)^{*}\end{array}$ \\
\hline 2008 & $\begin{array}{r}117,827 \\
(58,230)^{*}\end{array}$ & $\begin{array}{r}0,049 \\
(0,037)\end{array}$ & $\begin{array}{r}94.2433 \\
(45.2176)^{*}\end{array}$ & $\begin{array}{r}0.0439 \\
(0.0320)\end{array}$ & $\begin{array}{r}96.703 \\
(38.814)^{*}\end{array}$ & $\begin{array}{r}0.0503 \\
(0.0282)^{*}\end{array}$ & $\begin{array}{r}81,599 \\
(2,124)^{*}\end{array}$ & $\begin{array}{r}0.0503 \\
(0.0282)^{*}\end{array}$ \\
\hline
\end{tabular}

Fonte: Resultados da pesquisa.

${ }^{*}$ Coeficientes significativos a $10 \%$. 
Tabela A4 Resultados das regressões lineares locais sem covariadas

\begin{tabular}{|c|c|c|c|c|c|c|c|c|}
\hline \multirow{4}{*}{ Variáveis } & \multicolumn{2}{|r|}{$\mathrm{TE}=1$} & \multicolumn{2}{|r|}{$\mathrm{TE}<=2$} & \multicolumn{2}{|r|}{$\mathrm{TE}<=3$} & \multicolumn{2}{|r|}{$\mathrm{TE}<=4$} \\
\hline & $\beta /(d p)$ & $\beta /(d p)$ & $\beta /(d p)$ & $\beta /(d p)$ & $\beta /(\mathrm{dp})$ & $\beta /(d p)$ & $\beta /(d p)$ & $\beta /(d p)$ \\
\hline & $(n=548)$ & $(n=548)$ & $(n=1.526)$ & $(n=1.526)$ & $(n=1.746)$ & $(n=1.746)$ & $(n=2.286)$ & $(n=2.286)$ \\
\hline & Linear & Log & Linear & $\log$ & Linear & $\log$ & Linear & Log \\
\hline $\mathrm{R}^{2}$ & $0,28 \%$ & $0,82 \%$ & $0,17 \%$ & $0,51 \%$ & $0,31 \%$ & $0,61 \%$ & $0,46 \%$ & $0,71 \%$ \\
\hline Tempo & $-142,755$ & 0,060 & 503,639 & 0,014 & 881,416 & 0,180 & 45,034 & 0,013 \\
\hline Emprego - TE & $(91,221)$ & $(0,089)$ & $(619,745)$ & $(0,288)$ & $(911,379)$ & $(0,495)$ & $(309,551)$ & $(0,197)$ \\
\hline Recebeu & 77,928 & $-0,184$ & $-420,728$ & $-0,156$ & $-628,996$ & $-0,267$ & $-109,085$ & $-0,151$ \\
\hline Seguro - RS & $(155,803)$ & $(0,133)$ & $(421,565)$ & $(0,196)$ & $(568,353)$ & $(0,310)$ & $(252,977)$ & $(0,158)$ \\
\hline IF $* P S S$ & & & $-794,132$ & 0,065 & $-1.306,707$ & $-0,136$ & $-122,355$ & 0,061 \\
\hline It"KJ & & & $(999,788)$ & $(0,455)$ & $(1.374,930)$ & $(0,721)$ & $(458,830)$ & $(0,301)$ \\
\hline$(\mathrm{TF})^{2}$ & & & 147,737 & $-0,018$ & 316,571 & 0,029 & 2,249 & $-0,022$ \\
\hline$(\text { (It) })^{2}$ & & & $(205,138)$ & $(0,095)$ & $(354,507)$ & $(0,189)$ & $(89,435)$ & $(0,059)$ \\
\hline$(\pi)^{3}$ & & & & & $-17,355$ & $-0,009$ & 2,868 & $-0,002$ \\
\hline (II) & & & & & $(18,219)$ & $(0,011)$ & $(6,347)$ & $(0,004)$ \\
\hline$(\mathrm{TE})^{4}$ & & & & & $-16,680$ & $-0,003$ & 0,412 & 0,0003 \\
\hline & & & & & $(17,905)$ & $(0,009)$ & $(2,850)$ & $(0,001)$ \\
\hline
\end{tabular}

Fonte: Resultados da pesquisa. 
Tabela A5 Resultado propensity score matching

\begin{tabular}{|c|c|c|c|c|}
\hline \multirow{4}{*}{ Variáveis } & \multicolumn{2}{|r|}{ Pareamento } & \multicolumn{2}{|c|}{ Checagempareamento } \\
\hline & Salário (R\$) & Salário Log & Salário (R\$) & Salário Log \\
\hline & $\beta /(d p)$ & $\beta /(d p)$ & $\beta /(d p)$ & $\beta /(d p)$ \\
\hline & $(n=2.541)$ & $(n=2.541)$ & $(n=2.541)$ & $(n=2.541)$ \\
\hline Nordeste & $\begin{array}{r}-0,153 \\
(0,125)\end{array}$ & $\begin{array}{r}-0,159 \\
(0,126)\end{array}$ & $\begin{array}{r}-0,153 \\
(0,125)\end{array}$ & $\begin{array}{r}-0,158 \\
(0,126)\end{array}$ \\
\hline Sudeste & $\begin{array}{r}-0,261 \\
(0,120)^{*}\end{array}$ & $\begin{array}{r}-0,267 \\
(0,120)^{*}\end{array}$ & $\begin{array}{r}-0,261 \\
(0,260)\end{array}$ & $\begin{array}{r}-0,267 \\
(0,230)\end{array}$ \\
\hline Sul & $\begin{array}{r}-0,445 \\
(0,149)^{*}\end{array}$ & $\begin{array}{r}-0,452 \\
(0,149)^{*}\end{array}$ & $\begin{array}{r}-0,445 \\
(0,449)\end{array}$ & $\begin{array}{r}-0,452 \\
(0,492)\end{array}$ \\
\hline Centro-Oeste & $\begin{array}{r}-0,031 \\
(0,223)\end{array}$ & $\begin{array}{r}-0,037 \\
(0,224)\end{array}$ & $\begin{array}{r}-0,031 \\
(0,223)\end{array}$ & $\begin{array}{r}-0,037 \\
(0,224)\end{array}$ \\
\hline Homem & $\begin{array}{r}0,323 \\
(0,093) \\
\end{array}$ & $\begin{array}{r}0,322 \\
(0,093)\end{array}$ & $\begin{array}{r}0,323 \\
(0,382)\end{array}$ & $\begin{array}{r}0,322 \\
(0,285)\end{array}$ \\
\hline $\begin{array}{l}\text { Ensino Funda- } \\
\text { mental }\end{array}$ & $\begin{array}{r}-0,112 \\
(0,179)\end{array}$ & $\begin{array}{r}-0,123 \\
(0,179)\end{array}$ & $\begin{array}{r}-0,112 \\
(0,179)\end{array}$ & $(0,179)$ \\
\hline Ensino Médio & $\begin{array}{r}-0,101 \\
(0,186)\end{array}$ & $\begin{array}{r}-0,112 \\
(0,186)\end{array}$ & $\begin{array}{r}-0,101 \\
(0,186)\end{array}$ & $\begin{array}{r}-0,112 \\
(0,186)\end{array}$ \\
\hline Ensino Superior & $\begin{array}{r}0,122 \\
(0,206)\end{array}$ & $\begin{array}{r}0,110 \\
(0,206)\end{array}$ & $\begin{array}{r}0,122 \\
(0,206)\end{array}$ & $\begin{array}{r}0,110 \\
(0,206)\end{array}$ \\
\hline Carteira & $\begin{array}{r}-0,334 \\
(0,086)^{*}\end{array}$ & $\begin{array}{r}-0.335 \\
(0,086)^{*}\end{array}$ & $\begin{array}{r}-0.334 \\
(0,360)\end{array}$ & $\begin{array}{r}-0,335 \\
(0,368)\end{array}$ \\
\hline Branca & $\begin{array}{r}0,002 \\
(0,119)\end{array}$ & $\begin{array}{r}0,003 \\
(0,119)\end{array}$ & $\begin{array}{r}0,001 \\
(0,117)\end{array}$ & $\begin{array}{r}0,003 \\
(0,119)\end{array}$ \\
\hline Parda & $\begin{array}{l}-0,073 \\
(0,118)\end{array}$ & $\begin{array}{l}-0,074 \\
(0,118)\end{array}$ & $\begin{array}{l}-0,073 \\
(0,118)\end{array}$ & $\begin{array}{l}-0,074 \\
(0,118)\end{array}$ \\
\hline Chefe & $\begin{array}{r}0,038 \\
(0,105)\end{array}$ & $\begin{array}{r}0,035 \\
(0,105)\end{array}$ & $\begin{array}{r}0,038 \\
(0,105)\end{array}$ & $\begin{array}{r}0,035 \\
(0,105)\end{array}$ \\
\hline Filho & $\begin{array}{r}0,099 \\
(0,121)\end{array}$ & $\begin{array}{r}0,097 \\
(0,121)\end{array}$ & $\begin{array}{r}0,099 \\
(0,121)\end{array}$ & $\begin{array}{r}0,097 \\
(0,121)\end{array}$ \\
\hline $\begin{array}{l}\text { De } 26 \text { até } 35 \\
\text { anos }\end{array}$ & $\begin{array}{r}0,033 \\
(0,016)^{*}\end{array}$ & $\begin{array}{r}0,033 \\
(0,016)^{*}\end{array}$ & $\begin{array}{r}0,033 \\
(0,096)\end{array}$ & $\begin{array}{r}0,033 \\
(0,096)\end{array}$ \\
\hline $\begin{array}{l}\text { De } 36 \text { até } 45 \\
\text { anos }\end{array}$ & $\begin{array}{r}0,093 \\
(0,119)\end{array}$ & $\begin{array}{r}0,091 \\
(0,119)\end{array}$ & $\begin{array}{r}0,093 \\
(0,119)\end{array}$ & $\begin{array}{r}0,091 \\
(0,119)\end{array}$ \\
\hline $\begin{array}{l}\text { De } 45 \text { até } 55 \\
\text { anos }\end{array}$ & $\begin{array}{r}0,260 \\
(0,148)^{*}\end{array}$ & $\begin{array}{r}0,262 \\
(0,148)^{*}\end{array}$ & $\begin{array}{r}0,260 \\
(0,265)\end{array}$ & $\begin{array}{r}0,262 \\
(0,148)\end{array}$ \\
\hline Acima de 55 anos & $\begin{array}{r}0,289 \\
(0,274)\end{array}$ & $\begin{array}{r}0,286 \\
(0,273)\end{array}$ & $\begin{array}{r}0,289 \\
(0,274)\end{array}$ & $\begin{array}{r}0,286 \\
(0,273)\end{array}$ \\
\hline
\end{tabular}




\begin{tabular}{|c|c|c|c|c|}
\hline \multirow{4}{*}{ Variáveis } & \multicolumn{2}{|r|}{ Pareamento } & \multicolumn{2}{|c|}{ Checagempareamentc } \\
\hline & Salário (R\$) & Salário Log & Salário (R\$) & Salário Log \\
\hline & $\beta /(d p)$ & $\beta /(d p)$ & $\beta /(d p)$ & $\beta /(d p)$ \\
\hline & $(n=2.541)$ & $(n=2.541)$ & $(n=2.541)$ & $(n=2.541)$ \\
\hline Agrícola & $\begin{array}{r}0,018 \\
(0,194) \\
\end{array}$ & $\begin{array}{r}0,018 \\
(0,194) \\
\end{array}$ & $\begin{array}{r}0,018 \\
(0,194) \\
\end{array}$ & $\begin{array}{r}0,018 \\
(0,194)\end{array}$ \\
\hline Indústria & $\begin{array}{r}0,188 \\
(0,129) \\
\end{array}$ & $\begin{array}{r}0,189 \\
(0,129)\end{array}$ & $\begin{array}{r}0,188 \\
(0,129)\end{array}$ & $\begin{array}{r}0,189 \\
(0,129)\end{array}$ \\
\hline Comércio & $\begin{array}{r}0,256 \\
(0,131)^{*}\end{array}$ & $\begin{array}{r}0,257 \\
(0,131)^{*}\end{array}$ & $\begin{array}{r}0,256 \\
(0,132) \\
\end{array}$ & $\begin{array}{r}0,257 \\
(0,131)\end{array}$ \\
\hline Transporte & $\begin{array}{r}0,304 \\
(0,169)^{*}\end{array}$ & $\begin{array}{r}0,306 \\
(0,169)^{*}\end{array}$ & $\begin{array}{r}0,304 \\
(0,367)\end{array}$ & $\begin{array}{r}0,306 \\
(0,365)\end{array}$ \\
\hline Serviços & $\begin{array}{r}0,261 \\
(0,153)\end{array}$ & $\begin{array}{r}0,265 \\
(0,153)^{*}\end{array}$ & $\begin{array}{r}0,2651 \\
(0,243)\end{array}$ & $\begin{array}{r}0,265 \\
(0.256)\end{array}$ \\
\hline Adm. Pública & $\begin{array}{r}0,189 \\
(0,250) \\
\end{array}$ & $\begin{array}{r}0,189 \\
(0,250) \\
\end{array}$ & $\begin{array}{r}0,187 \\
(0,190) \\
\end{array}$ & $\begin{array}{r}0,189 \\
(0,250) \\
\end{array}$ \\
\hline Outras Atividades & $\begin{array}{r}0,104 \\
(0,158)\end{array}$ & $\begin{array}{r}0,105 \\
(0,158)\end{array}$ & $\begin{array}{r}0,104 \\
(0,158)\end{array}$ & $\begin{array}{r}0,105 \\
(0,158)\end{array}$ \\
\hline 2009 & $\begin{array}{r}0,565 \\
(0,091)^{*}\end{array}$ & $\begin{array}{r}0,566 \\
(0,091)^{*}\end{array}$ & $\begin{array}{r}0,565 \\
(0,467) \\
\end{array}$ & $\begin{array}{r}0,566 \\
(0,464) \\
\end{array}$ \\
\hline 2008 & $\begin{array}{r}0,487 \\
(0,107)^{*}\end{array}$ & $\begin{array}{r}0,487 \\
(0,107)^{*}\end{array}$ & $\begin{array}{r}0,487 \\
(0,490)\end{array}$ & $\begin{array}{r}0,487 \\
(0,498)\end{array}$ \\
\hline
\end{tabular}

Fonte: Resultados da pesquisa.

* Coeficientes significativos a 10\%. 